\title{
Current trends in protein purification : A Review
}

Angela Boxi ${ }^{1}$, Isha Parikh ${ }^{2}$, Radhika B $\mathrm{S}^{3}$, Shryli K $\mathrm{S}^{4}$

Amity University Kolkata ${ }^{1}$, D. Y. Patil School of Biotechnology and Bioinformatics², Sri Venkateswara College of Engineering ${ }^{3}$, Yuvaraja's College (Autonomous) ${ }^{4}$

\section{ABSTRACT}

\section{Article Info}

Volume 7, Issue 6

Page Number: 279-310

Publication Issue :

November-December-2020

Article History

Accepted : 25 Nov 2020

Published : 03 Dec 2020
The present review is based on papers published between 1990 and 2020 and gives Comparative information about the most common protein purification techniques Gel-Filtration Chromatography, Ion-Exchange Chromatography, Electrophoresis, Affinity Chromatography, and Dialysis, High-Pressure Liquid Chromatography. and their applications.

Keywords : Gel-Filtration, Affinity Chromatography, Electrophoresis, Dialysis, High-Pressure Liquid Chromatography

\section{INTRODUCTION AND DISCUSSION}

Amino Acid Sequence variations in proteins identification by automated HPLC/Micro spray Tandem Mass Spectrometry

The paper helps in identification of the SNPs using Microcapillary HPLC-Mass Spectrometry. An advantage of the use of this technique is detection of sequence differences on the basis of $\mathrm{m} / \mathrm{z}$ value rather than different migration times on a gel or hybridization and duplex melting temperatures. It can be used for de novo identification of sequences or for the identification of proteins of known sequences. The technique helps to generate a complete sequence coverage for hemoglobin using automated tandem mass spectrometry data acquisition and a software to identify the site and type of variations that result from SNPs. No efforts were made to determine the limits of detection in this study. To obtain consistent $100 \%$ sequence coverage for hemoglobin, three processes were optimized: sample preparation, chromatographic separation of the digested protein mixture, and data collection on an LCQ ion-trap mass spectrometer. After isolation and purification of $\mathrm{Hb}$ and proteolytic digestion, three separate proteolytic digests were performed on each protein. They were then combined into one sample tube for subsequent LC/MS/MS analysis. Microcapillary HPLC-Mass Spectrometry, this method is selected for separation of $\mathrm{Hb}$ peptides from the combination digest. Peptide analyses is performed on Finnigan LCQ ion trap mass spectrometer. Spectra were acquired in automated MS/MS mode. During an automated run, if an ion was present in a scan above a specified threshold, a production spectrum was acquired. Analysis was done using SEQUEST computer algorithm, which allows for identification of amino acid substitutions. The SEQUEST-SNP program reads this database, dynamically generates all possible single-nucleotide polymorphisms (SNPs), translates these sequences to peptides, and analyses these peptides. Amino acid sequence variations were identified by using $\mu \mathrm{LC}$ MS/MS to generate tandem mass spectra to cover $99+\%$ 
of the protein's sequence. When these digests were combined into one tube, followed by a single $\mu \mathrm{LC}$ MS/MS analysis, $100 \%$ sequence coverage was achieved about half of the time, with $97 \%$ or greater coverage obtained in all attempted runs. Around 7580 peptides with overlapping sequences were produced per run using automated SEQUEST database searching. The complete or nearly complete sequence coverage is obtained for hemoglobin and is improved with this procedure. A rapid, automated method has been developed for obtaining $100 \%$ sequence coverage (in the majority of cases and over $97 \%$ coverage in all attempted analyses) in hemoglobin protein in a single LC-microspray tandem mass spectrometry experiment. This program rapidly identifies amino acid substitutions in a gene of interest by dynamically creating and translating a nucleotide database of SNPs. It is said that the future work will extend this method for the analysis of other proteins to acquire $100 \%$ sequence coverage from other proteins and to determine the limits of detection for the acquisition of complete sequence coverage of rare proteins. This method provides a strategy to identify amino acid sequence variations at the protein level, but additional efforts are needed to establish the limits of detection of the method and to develop strategies to quantitate protein expression levels.

This paper helps in identification of the aminoacid sequences of a protein molecule using micro capillary HPLC MS. This indicates that HPLC is not only used for purification of proteins and peptides but can also be used to identify the aminoacid sequences in order to detect the SNPs that causes particular kind of disease.This helps us to understand that the aminoacid sequences in protein can be identified using HPLC in combination with MS. The study helps our research by providing a better understanding of a more sophisticated technique that can help in protein purification as well as amino acid identification.
Identification of proteins from complex mixtures using three different directly coupled HPLC MS/MS strategies and its comparison: single-dimension LCMS/MS, 2-phase MudPIT, and 3-phase MudPIT.

Multidimensional HPLC separation techniques provide access to even more complex mixtures of proteins where three strategies are coupled with HPLC MS and are called multidimensional protein identification technology (MudPIT). A biphasic column is used with a reversed phase (RP) material and flanked by a strong cation exchange (SCX) resin that allows multidimensional separation of peptides. The tandem mass spectrometry data is correlated to the database sequences and the peptides are identified by their amino acid sequence. LC-MS/MS has proven successful for the analysis of numerous proteins and protein complexes. The sample is offline desalted and loaded onto a 2-phase MudPIT column, whereas in 3phase MudPIT column it is loaded directly. Inorder to compare the techniques a protein mixture that contains more than 200 types of protein is selected (bovine brain microtubules). The analysis was done on the basis of the returns of number of proteins by each technique. There could be many sets of protein paralogs present within the sample, they were not counted separately for analysis if there were not peptides specific for that particular protein. After the minimization filtering, the results were 26,55 , and 62 proteins for the 1D, 2-phase, and 3-phase experiments respectively. These results were to be expected because of the greater resolving power of the MudPIT columns and the fact that data were collected over a six-fold greater time period. More differences were seen in the total number of peptides matching to these proteins. For 1D LC-MS/MS 147 individual peptides were found and for 2-phase and 3-phase MudPITs 341 and 431 peptides respectively. None of these analyses was sufficient to return more than 200 proteins that previously have been shown to be present in the sample. By analyses using more sample, a longer analysis time, and more comprehensive 
database searches 3-phase MudPIT column was concluded to be superior both in number of proteins and number of peptides that were sampled. However, the choice of strategy depends on the complexity of the sample, the amount of starting material available, and the level of analysis needed. If it were only necessary to identify the most abundant proteins within this sample or the sample was significantly less complex, then 1D LC-MS/MS would be preferred because it is faster and more easily automated. 3phase MudPIT is an excellent choice when a robust analysis is required on very small quantities of a protein mixture. This paper talks about advanced HPLC techniques used for identification and separation of proteins and peptides. These three strategies can be used depending upon the objective of the experiment. LC-MS can be used to identify most abundant protein in the sample. 3-phase MudPIT can be used when very small quantity of protein is required to be identified. This paper helps our research by giving us an indept idea about the use of HPLC coupled with other strategies for identification of proteins and peptides. HPLC is a widely used tool along with other procedures to identify peptides and proteins present in complex samples.

\section{Overview of proteomics analysis using HPLC}

Newly developed techniques for separation of proteins and peptides in the sample using one dimensional HPLC and multi-dimensional HPLC are mentioned in the paper. A limited amount of HPLC advanced techniques have been mentioned. It is important to develop the HPLC technique by increasing its sensitivity in detection of proteins by using separation columns of smaller diameter and decreasing the flow rate. The instrumentation of the conventional HPLC does not differ from the one used for proteins and peptides. The only difference is the column and the magnitude of the flow rate. For increasing the sensitivity the columns have undergone three important developments i.e. changes in RP stationery phase, monolithic columns and miniaturized columns in form of chips. All the conventional HPLC detectors are used for proteome analysis. Nano-HPLC is the widely used separation technique that increases sensitivity compared to conventional HPLC. The most used separation technique is the reversed phase HPLC (RP) for proteome analysis. Combination of reversed phase separation column with other columns such as ion exchange (IEX) or immobilized metal-ion affinity chromatography (IMAC), the amount and quality of analytical information can be highly increased. Analysis of post translational modifications (PTM) is more difficult than for non-modified proteins. This is because the proteins are modified to a low stoichiometry and the peptide-modification bond is often very labile. Analysis is done using monolithic columns where water is used as mobile phase and does not need any organic solvents reducing the risk of removing or masking existing PTMs on a peptide for detection. HPLC separation of a group of proteins and peptides can include almost all the HPLC technologies presently known: RPC, affinity chromatography, IEX chromatography, size exclusion chromatography, the use of monolithic stationary phases and miniaturized separation systems, etc.

The separation of phosphorylated peptides are by 2DE mapping on cellulose plates that is by one and twodimensional high-resolution gel electrophoresis, RPC, IMAC and by combining anion exchange chromatography and RPC. The HPLC system connected to the mass spectrometer helps the analysis of highly complex samples without a need to perform radio-active labelling of the peptides. Phosphopeptides show a high affinity for metal surfaces and form complexes with the metal surfaces of HPLC apparatus. This kind of risk can be lowered if HPLC systems with polyether ether ketone (PEEK) or 
titanium injectors, filters and column frits are used. Even with these limitation factors, RPC is widely used for separation of samples with phosphopeptides because of its easy coupling with ESI-MS or with offline fraction collection and MALDI-MS.

Titanium columns stationary phase was introduced for the purpose of selective enrichment of phosphopeptides which improved trapping of phosphorylated peptides onto the self-packed titanium trap columns. This can increase the number of detection of the phosphorylated sites. An automated column switching with MS detection of phosphopeptides was introduced. Phosphorylated proteins and peptides show a high affinity towards metal ions and form quite stable complexes with them. Proteins are proteolytically digested and they are loaded onto the immobilized metal affinity column. Along with phosphopeptides which bind on to such a column, the acidic non-phospho peptides also bind. To minimize the non-specific binding of acidic peptides, they are converted to free carboxyl groups of the peptides in solution to the corresponding methyl esters and then analysed with IMAC and nano-HPLC-MS. The coupling of metal-ion affinity chromatography and reversed phase trap along with the separation columns was automated and online, which gives higher sample throughput. This approach not only identifies but also quantifies phosphopeptides if the methanol used for esterification is replaced by deuterated methanol. Even though IEX chromatography is a routine for separation and purification of crude protein samples, it is used only sporadically for peptide separation in combination with nano-HPLC for complex proteomic samples.

Multidimensional separation techniques have been introduced to improve resolution. IEX chromatography is generally the first step before the nano RP-HPLC. It is used for complex peptide samples. Multidimensional chromatography does not only imply the separation of peptides in the first dimension, but also the 'top-down' approach, which is the separation of proteins in the first dimension along with subsequent RP separation and mass spectrometric detection of proteins. All separations in chromatography benefits from high resolution, high column capacity, fast separations and low back pressures. This can be achieved by using monolithic columns for separations in proteomics. Monolithic columns are easy to prepare and function, they have enhanced mass transfer, high column efficiency and they are more robust compared to pellicular HPLC columns. Their limitation is that they are very easily overloaded. One possible way to resolve these problems is to use serial linkage of these columns. It is also used for online enzymatic reactors. This approach requires further reserach but it seems to be promising with respect to increasing the sample throughput. The miniaturized chips are used for separation of proteins and peptides. Majority of chip developments are focused on electrophoresis, not on HPLC. The new chip designed to use existing nano-HPLC hardware and MS is developed.Small particles used for the stationary phase improves the peak shape and increase the column resolution. The results are achieved with UPLC which is significantly better in comparison to the results achieved with conventional HPLC. HPLC in proteomics is commonly used and accepted for separation of proteins and peptides. Development of ICAT and monolithic columns as well as the development of new affinity column media like titanium and zinc have introduced new tools for selective sample clean up and enrichment helping the researcher to dig deeper into the proteome. UPLC and miniaturization of separation systems on a chip can change the profile of separation techniques for proteomics. A number of different techniques have been developed by making few modifications in the conventional HPLC. This paper focuses on important high-end thoroughput variants of HPLC that have been tried and tested. There are many other techniques other than these. Among all 
the techniques used miniaturization and UPLC are the most advanced techniques that can give better resolution for protein sample purification and analysis.

This paper gives a detailed insight and examples of few advanced HPLC variants that have been used for proteome analysis. However, the author mentions that there are many other variants, which we will have to look into for our research.

\section{One-step purification method for recombinant protein from a whole cell extract by RP-HPLC}

In this an easy and a flexible method for purification of proteins from cell lysate is developed even if the concentration is less. It is a scalable, one step method based on RP-HPLC. It produces high yield of product with goo purity compared to affinity chromatography. Affinity chromatography is highly time consuming and expensive for scaleup. It has other disadvantages like sample handling, concentration steps, dialysis, time consuming and loss of purified sample. RPHPLC has an excellent resolving power and scale-up ability. However, researchers are concerned with its protein denaturation ability that causes activity loss. The value of slow acetonitrile gradients $(0.1-0.2 \%$ acetonitrile/min) to utilize more efficiently the hydrophobic stationary phase of RP-HPLC for peptide separations compared to the more traditionally employed conditions of $0.5-1 \%$ acetonitrile/min) is demonstrated resulting in efficient preparative purification. It avoids the necessity for the use of increasingly larger columns in order to maintain satisfactory levels of product purity and yield with concomitant higher operating costs in terms of packing, equipment and solvents. It has developed a general one-step facile, flexible and readily scalable purification method for recombinant proteins, based on RP-HPLC. Affinity purification of the fusion protein (TM 1-99) produced product with an excellent purity of $>99 \%$. However, two-step protocol resulted in a considerable reduction in protein yield compared to the one-step affinity purification.

The one step preparative RP-HPLC of the fusion protein was developed as a flexible purification approach was as follows: a rapid rise to an acetonitrile concentration $15 \%$ below that of the eluting concentration during the analytical gradient elution run. This was followed by a slow gradient, a rapid rise to a concentration of acetonitrile known from an analytical run to be enough to ensure elution of all crude sample components from the column and by an isocratic wash at this high concentration of acetonitrile. The advantage of slow gradient approach is the high sample loading that concentrates the desired material on the column aiding its separation from closely adjacent impurities. Multisite binding of proteins and peptides to the hydrophobic matrix prevents their elution until the acetonitrile concentration approaches that required to elute them during an analytical run that is peptides and proteins exhibit only narrow partitioning windows. Another advantage is the large range of sample loads and is a good compromise between the time taken for efficient product purification and obtaining maximum sample load. One step preparative RP-HPLC with trace amounts is also a very effective separation with a purity of $>94 \%$. The efficacy of the slow gradient approach is excellent, with concomitant concentration of desired product, to purify even trace levels of product from a crude lysate. In RP-HPLC of fusion protein the desired protein is clearly identifiable due to over-expression. Negligible overlap between purified product and hydrophilic or hydrophobic impurities, an excellent purification of TM 1-99 was achieved. A second purification is carried out with approximately double the sample load which also gives purified product. However, further increase in the sample load gives 65\% recovery, which indicates that the capacity of the column is exceeded. One step RP-HPLC produces 10x improvement in yield of highly purified material 
when compared to affinity chromatography. It is comparatively less expensive to scaleup with one step RP-HPLC. There is less loss of product that was caused due to multi-step procedures. 100x improvement in yield of highly purified product compared to a two-step affinity/RP-HPLC approach, i.e., a considerable amount of product was lost when combining the affinity and RP-HPLC modes and there is little improvement in product purity was achieved by the two-step approach $(>99 \%)$ compared to the one-step protocol (>94\%). One-step RP-HPLC slow gradient approach shows good potential for purification of recombinant proteins from cell lysates, where high yields of purified product are achieved compared to affinity chromatography.

The paper develops a one-step method for producing better results with respect to scaleup and resolution. One step RP-HPLC is a better method compared to affinity chromatography as it provides better resolution while purification of proteins by focusing on one of the type of HPLC that is RP-HPLC. It compares HPLC with affinity chromatography and provides proof as to why RP-HPLC is a preferred method over affinity chromatography for protein purification.

\section{Separation of proteins using liquid chromatography}

The nano detection property of the chromatography techniques makes it more useful in proteomic research. Reversed phase high performance liquid chromatography is the most popular, as it has a wide range of applications. The on-line coupling of this technique with sample preparation and detection units like MS; makes it ideal technique in proteomics research. Most advanced microchip-based instruments are used to achieve difficult tasks. The author has mentioned a number of research papers that use RP-HPLC for separation of proteins. One of the example given is the quantification of a group of gene products (1600) into 997 protein families with 830 membrane or membrane-bound proteins in normal and malignant breast cancer cells. Electrospray ionization mass spectrometric method and tandem-mass spectrometry were also used for analysis and identification. Affinity HPLC is a chromatographic method capable to separate biochemical mixtures which are highly specific in nature. A stationary phase that reversibly binds to a known subset of molecules just by combining affinity chromatography can be designed. It exploits a known and defined property of analytes which can be used during purification process. The process can be considered as an entrapment with the target molecule trapped on a stationary phase while the other molecules in solution do not trap due to lack of this property. Many examples have been given where affinity HPLC is used. Tumor necrosis factor receptor (factor 6) binding proteins have many heat shock proteins, in osteoclast cells are seperated using affinity chromatography followed by mass spectrometric technique. Immobilized metal affinity chromatography is also used for the purification of phosphopeptides. Gel Permeation HPLC works on the principle of sizes of the compounds and in this big size molecules eluted first followed by small size molecules. It includes the transport of a liquid mobile phase through a column containing a porous material as stationary phase. It also called as size-exclusion chromatography and is a rapid method for the separation of polymeric species. Thus, it is a method of choice for separation of biomolecules such as peptides, proteins, enzymes. Many examples and use of gel permeation HPLC are given. Separation and isolation of proteins from rat liver nuclei by using microcystin- Sepharose chromatography followed by mass spectrometry was performed. In ligand exchange-HPLC the RP column is replaced by ion exchange column which makes it an advanced version of RP-HPLC. It is widely used for the analysis of all inorganic and organic ionic species. In LE-HPLC, anion and cation exchange columns or mixed (anion and cation) columns are available which improves the 
separation efficiency. The stationary phase is composed of resins of negative charges and cation metallic species are attracted to the stationary phase by electrostatic interactions in cation exchange chromatography. In anion exchange chromatography, the stationary phase is a resin containing primary or quaternary amine functional groups. Quantification of membrane proteins of wild type Corynebacterium glutamicum and L-lysine producing strain is performed using anion LE-HPLC. They even identified the proteins in the membrane of either wild type or the L-lysine. Capillary HPLC combines high peak efficiency which is characteristic of electrically driven separations with high separation selectivity. Capillary HPLC experiments are carried out on open tubular capillaries or capillaries packed with particulate or monolithic silica or other inorganic materials as well as organic polymers. The electrophoretic and chromatographic mechanisms work simultaneously in capillary HPLC and several other combinations are also possible. The separation and identification of few proteins were performed in foam cells with capillary liquid chromatography followed by mass spectrometry. Number of studies are mentioned. One of it is the identification of 111 human nasal mucous proteins in nasal lavage fluids (NLFs) of ten volunteers (patients) using a capillary liquid chromatography-electrospray quadrupoletime-of-flight mass spectrometric method. All various chromatographic methods are used in proteomic analyses. The application of these procedures from most used to least is reversed phase >gel permeation $>$ ligand exchange $>$ affinity. There are a number of papers in which RP-HPLC is widely used compared to the other methods. It has different stationary phases available, which can be used for analyses of proteomes. They are capable to work with a wide range of mobile phases, enhancing the application range of reversed phase chromatography. Gel permeation HPLC is useful for proteomic separation and identification because of wide variation in the sizes of proteins. Proteins have charges, thus, Ligand exchange is also useful. Affinity and capillary electro chromatographic techniques are also used in proteomic area. Liquid chromatography is a back bone of the separation science. With the hyphenation of mass spectrometer detectors with this technique has achieved heights in analysis work. The study compares the different types of HPLC that are available. The paper gives a number of examples in which different kinds of HPLC are used. On comparing the number of available paper, it can be noted that RP-HPLC is widely used followed by GPHPLC. The use of the HPLC technique highly depends on the type of the sample. This paper helps our research as it mentions a number of examples of HPLC and its types. It can be well concluded from this paper that HPLC is widely used separation technique for proteins and amongst its types RPHPLC is widely used.

\section{Multidimensional protein purification system based on standard HPLC}

The paper points out at the changes made in model Äkta Explorer high-performance liquid chromatography (HPLC) system to overcome all the drawbacks present in the past model that was developed for 3D purifications. Protein purification protocols require to be highly reproducible. Many protein purification protocols involve sequential separation over a number of chromatographic columns that work according to different separation principles to give highest purity. The procedure is very time consuming and the sample recovered between re-injection between the columns is limited. It allows the connection of only 11 buffers. The problem is solved by adding two valves, a flow restrictor, tubing connections and a Linux PC. In the new developed model, is an automated setup for $4 \mathrm{D}$ and higher dimensional protein purification remotely controlled by the internet. The procedure is completed in $19 \mathrm{~h}$ and yield protein of high quality. 
The system software used is UNICORN 5.01. His6tagged heterotrimeric $\alpha 2 \beta 2 \gamma 1$ AMP activated protein kinase [AMPK (9-11)] was successfully purified using the new model. Compared to manual handling, the setup improves the reliability of multidimensional protein purification. This paper elaborates on the changes made in the Äkta Explorer HPLC that was available for $3 \mathrm{D}$ purification. The new model has been experimented and used and is faster by $80 \%$ compared to the other manual operation. All the drawbacks have been thoroughly looked into and solutions have been provided. The new model is fully automated, faster, gives high purity and can be used with $4 \mathrm{D}$ and larger molecules and helps in understanding that the traditional HPLC has been developed over the years and now is fully automated and can purify $4 \mathrm{D}$ and more complex molecules of proteins. It needs to be researched if more advanced models are available for use.

\section{Principle, method \& application of HPLC}

This paper describes different types of High Performance Liquid chromatography methods with respect to its principle, methods and its applications related to proteins and peptides. HPLC works on the principle of column chromatography and is used for analysis of different biomolecules. The liquid mobile phase that contains the sample at high pressure flows through the column packed with suitable matrix. Separation is through differential interaction of molecules with the column matrix. The high pressure increases the flow rate which decreases the time required for separation. The signals generated by the separation are detected with the help of a software. The different types of HPLC are differentiated on the basis of stationary phase used.

In Reverse phase chromatography(RPC), the separation occurs through adsorption of the protein molecules with the stationery phase or by using the property of hydrophobicity of the protein molecules.
REC has a high resolution, reproducible and a robust procedure. Denaturation of proteins takes place in this kind of HPLC due to the harsh conditions. Thus, when functionally active proteins are required, this method cannot be used.

In ion-exchange chromatography(IEXC), the molecules are separated because of the difference in its charges. The stationary phase is either positive (cation exchange chromatography) or negative (anion exchange chromatography). IEXC is a highly selective chromatography technique that resolves proteins that differ by a single aminoacid. In affinity chromatography(AC), the proteins bind to specific reversible ligands coupled to the matrix inorder to separate it from the mixture. The use of ligand in AC, makes it a highly selective procedure. The attachment of the molecules to the ligands is reversible. AC is a faster method as it is a single step procedure. In size exclusion chromatography(SEC), separation occurs on the basis of the size and shape of the protein or peptide molecule. It exploits the molecular sieve property of the porous matrix. There are two types of column used in SEC hydrophobic column (gel permeation) and hydrophilic column (gel filtration). Compared to adsorption chromatography, the size of the gel pore is smaller and not uniform which plays an important role in separation. The height of the packaging bed affects both resolution and the separation time. Larger bed height gives a better resolution but it takes more time to run a separation. Thus, IEXC and AC are highly selective techniques which can be used for separating particular type of proteins. REC can be used when protein in its active form is not required, while if the active form is required then one can use SEC. Thus, REC is a laboratory based purification method for proteins while, SEC can be used as a final polishing step when the sample volume have been reduced for analytical protein purification. IEXC is used for protein purification and characterization which is often used in biopharmaceuticals to produce 
safe and effective drugs. AC can be used for separating the denatured form of protein from the functionally different forms. Thus different types of HPLC are used for different purposes. This paper gives a brief insight on the type of HPLC that should be used for the different types of samples of proteins and peptides. It also briefs about the principle, procedure and applications of these types of HPLC. However, this paper only highlights four different types of HPLC. There are many other types of HPLC. It does not mention any reason for the selection of only these four types of HPLC methods. More detailed study can be conducted and comparison can be made on the basis of the resolution and purification of proteins provided by the other types of HPLC.

\section{An Outline on Affinity Chromatography}

It provides an overview of affinity chromatography, from its discovery to various techniques that evolved from it. Affinity chromatography was introduced in 1968 by Pedro Cuatrecasas, Chris Anfinsen, and Meir Wilchek for purification purposes and it is also stated that it is used in $60 \%$ of all purification protocols. Affinity chromatography is a simple molecular recognition method, where a polymeric carrier with a recognition site captures the needed biomolecules when a cell extract is passed through the column, then those biomolecules are retrieved by changing some external conditions. Some biomolecules such as antibodies and antigens, Bacteria, Viruses and phages, genetically engineered proteins, Lectins and glycoproteins, Regulatory enzymes, and Receptors are purified by this technique. Few techniques evolved from affinity chromatography include Immunoaffinity, Hydrophobic, Metal-chelate, Dyeligand, and Lectin affinity chromatography. Silica, polysaccharides are used as carriers, but $95 \%$ use Agarose Sepharose. Affinity chromatography is a 5 step process that involves 1) matrix activation 2) coupling of ligands 3) protein adsorption 4) elution 5) matrix regeneration. The ability of an affinity to a column to recognize the soluble ligand is called recognition fidelity, where a dynamic equilibrium is maintained between the association and the disassociation macromolecules when eluted isocratically from the immobilized ligand under a non-chaotropic buffer, which directly depends on the equilibrium between the immobilized ligand and macromolecule interaction. As years passed, a Surface Plasmon Resonance biosensor was developed for the analysis of direct interaction, in which a gold sensor chip is coated with dextran where the immobilized ligand gets attached to it. The interaction of macromolecules while passing through the chip is detected by changes of refractive index at the old surface using the SPR. Automation in the analytical use of immobilized ligands seems likely to continue to evolve. It is concluded that affinity chromatography will show a powerful impact in the discovery of biomolecules and elucidation of molecular mechanisms of interaction underlying their bioactivities.

\section{Immobilized metal ion affinity chromatography of} proteins with chelated mercury as a ligand.

The retention properties of the iminodiacetate Sepharose gel column were used for the proteins with different levels of the eluting system along with its mercury leaching is studied. Immobilized metal ion affinity chromatography or metal chelate chromatography is based on the chelation of metal ions from the protein surface the principle behind this technique is the creation of high-affinity metal coordination sites with histidine residues by sitedirected mutagenesis. The recombinant protein chosen here for purification is bromelain and human recombinant granulocyte colony-stimulating factor (rhG-CSF) whose interaction with histidine and cysteine is absorbed. Sepharose CL-6B-IDA gel was synthesized and prepared for chromatography. Chromatography of bromelain is done with metalfree IDA gel along with pure rhG-CSF. The rhG-CSF 
inclusion body solubilizate is prepared and the eluates are assayed. rhG-CSF with chemical modification is prepared by a-carboxy amidation of unpaired cyc and modification of diethylpyrocarbonate in the His residues. The primary evaluation of the SepharoseIDA-Hg(II) column towards bromelain at ph7 didn't show metal ion function but showed its retention ability due to the addition of $\mathrm{Na}_{2} \mathrm{SO}_{4}$.In the presence of the same salt at a ph below pI the interaction of bromelain and rhG-CSF with chelated mercury ions is seen. When the studied retention was compared with rhG-CSF and $\mathrm{Hg}(\mathrm{II})$ - and $\mathrm{Ni}(\mathrm{II})$-loaded SepharoseIDA columns showed that histidine residues are suitable for the $\mathrm{SH}$ group interaction. The direct interaction of free reduced $\mathrm{SH}$ groups with the Sepharose-IDA-Hg(II) column might be possible when rhG-CSF inclusion bodies are chromatographed. Mercury is one of the toxic heavy metals and part of the functional groups containing phosphate, carboxyl, etc. As the histidine residues are not applicable for the interaction of the $\mathrm{SH}$ group of the protein with chelated mercury, depending on this it is said that free SH group, histidine, and other amino acid chains get bonded to the mercury. It can be concluded that. mercury(II) in its chelated state can be used in protein chromatography through IMAC.

\section{A comparison study on protein purification by His- tag and GST-tag affinity chromatography}

Functional genomics includes the study of genes and their products, it also requires purifying proteins in a time and cost-effective manner. The proteins are expressed, fused to the affinity bags, and purified using hexahistidine tag (His-tag) or glutathione Stransferase (GST)-tag, which resulted in higher yields by metal chelation or glutathione affinity chromatography. The proteins are expressed in E.Coli SCS1 cells and expressed in (pQTG) vector which causes the fusion of the protein to N-terminal HisGST-fusion, it is then purified by metal chelate affinity matrix or glutathione agarose. Proteins are expressed in 96 well plates and His-tagged and GSTtagged proteins are purified by Robot. Ni-NTA agarose or glutathione agarose beads are equilibrated in wash buffer and it is made to bind to the protein and it is shaken so that beads settle at the bottom, the beads are then transferred to 96 well plates with large pore polyethylene frits. The protein solution elution buffer is added and protein concentration is determined by SDS-PAGE and the gels were stained with coomassie brilliant blue. Optimization for purifying affinity tag proteins found that the ratio of bead volume to liquid volume during the binding step was crucial for binding efficiency to be kept low. It was seen that the purification yield of the protein varied due to the attribution of different amounts of elute volume recovered after elution. Glutathione affinity chromatography yielded a low amount of protein when compared to Ni-NTA affinity chromatography due to the incomplete elution and binding of the expressed protein from the glutathione support/resin. As a fully automated, efficient, and reproducible method was used to purify proteins in 96 well plates it showed high throughput expression screening. The purity of both His- and GST- tagged proteins with Ni-NTA or glutathione agarose were similar but the yield was high in Ni-NTA agarose due to the incomplete elution of GST-tagged protein from glutathione agarose.

\section{Agarose and Polyacrylamide Beads Derivatives for} protein purification by affinity precipitation

The study involves the purification of protein by affinity chromatography through various agarose and polyacrylamide beads derivatives, where the ligand is attached to them through the bonds that are susceptible to chemical cleavage. The agarose adsorbents are prepared by coupling proteins and other small molecules to carbohydrate derivatives using cyanogen halides, whereas Polyacrylamide gels are commercially available in different forms and 
sizes. Based on this Sepharose (agarose derivative) was considered better than Sephadex (cross-linked dextran) due to their loose network. The ligand groups having a censorious link with macromolecules should be placed distant from the solid matrix to reduce the interference and for better purification. Sepharose is stored at $4^{\circ} \mathrm{C}$ and then the ligands are coupled to the amino group of the agarose. $\omega$ Aminoalkyl an agarose derivate was coupled to aminoethyl of the agarose through carboxylic acid ligand at ph above 10, on the other hand, $\mathrm{p}$ AminobenzamidoethyI-Sepharose and TyrosylSepharose were made and coupled through Azo linkage and Diazonium compounds respectively at $\mathrm{ph}$ 9.5 to 10 . The color test is done to distinguish various agarose and polyacrylamide derivatives, the result is derivatives containing primary aromatic amines: redorange, unsubstituted agarose or polyacrylamide beads: yellow, primary aliphatic amines: orange. etc. Ligand substitution was higher with polyacrylamide gels than agarose, but due to low porosity polyacrylamide beads are limited for usage in affinity chromatography. The intact protein-ligand complex is removed from the solid support to elute proteins that are bound to the column without utilizing the extreme condition.

\section{High protein yield and High-throughput protein purification by affinity chromatography}

One of the vital strides in high-throughput protein production is protein purification, a recently grown high return protein purification, and segregation strategy permits completely mechanized purification of 60 cell lysates with milligram yields of pure recombinant protein in $18.5 \mathrm{~h}$. This depends on affinity chromatography that has been set up on an instrument that uses positive pressure instead of vacuum for a fluid exchange through columns. A convention is introduced that incorporates all means of equilibration of the chromatography wash and elution. Positive pressure and individual pumps for every fluid channel add to controlled stream rates. The most utilized method is Immobilized metal affinity chromatography with poly-histidine labels as purification handles. Hexa-histidine albumin binding protein (His $6 \mathrm{ABP}$ ) and different target proteins with His 6 ABP were expressed in E.coli BL21 (DE3) cells and then subjected to purification on an ASPEC XL4 four-probe SPE system controlled by 735 Sampler software 5.2, with three parts, a pump unit, a robotic arm with tubing connected to the pump unit, and a working table. The working table was equipped with thermo-stated blocks that can contain up to 60 tubes at temperatures from 4 to $40^{\circ} \mathrm{C}$. IMAC columns were first equilibrated with a $20 \mathrm{~mL}$ denaturing washing buffer, with a flow rate of $2 \mathrm{~mL} / \mathrm{min}$. Cell lysates were then added to the columns at a flow rate of $0.35 \mathrm{~mL} / \mathrm{min}$ and were washed using denaturing buffers. Elution of purified protein was accomplished with denaturing the elution buffer at $2 \mathrm{~mL} / \mathrm{min}$ and the eluates were collected and moved to the precooled rack by the four probes. The eluted proteins were then analyzed by SDS-PAGE and the concentration was determined. The purification protocol was shown to be highly reproducible through the purification of five identical cell lysates for four different proteins. The main advantage of this technique is it is a bench-top instrument and the high yield, reproducibility is by the precise control of flow rates achieved by the positive pressure. In contrast to many purification strategies, this eliminates the risk of introducing air into the chromatography media that may result in poor chromatography and foaming. The microtiter format gives a high throughput, but gives limitations in the sample and resin volumes and is thus better suited for a moderate yield of protein. Hence this method can be said to be reliable and robust, also without any thermal degradation, which some purification strategies suffer.

Affinity chromatography on cyclodextrin-modified agarose for the Purification of prenylated proteins. 
This study states that the sepharose medium chemically functionalized with $\beta$-cyclodextrin $(\beta-C D)$ is effective for the purification of prenyl proteins from non-prenylated families through affinity chromatography. Prenylation is a post-translational modification that involves the addition of farnesyl or geranylgeranyl isoprenoid to a $\mathrm{C}$-terminal recognition sequence. The $\beta$-CD-Sepharose column was prepared by synthesizing $\beta$-CD-NH2 and conjugating it with the Sepharose-NHS. The column was then connected to HPLC and FPLC.On the other hand mutagenesis and overexpression of mcherry were performed and the obtained cell lysate was poured into the column and the protein was eluted. The enzyme reaction was carried to perform a prenylation reaction, the prenylated proteins were separated by FPLC. The mCherry-CVIA was made prenylated with $[3 \mathrm{H}]$ farnesyl diphosphate. Then mCherry-CVIAazide was immobilized onto the alkynefunctionalized agarose beads and finally prenylated mCherry-CVIA was purified using $\beta$-CD-Sepharose from the cell lysate by FPLC. It was seen that prenylated and unmodified mCherry-CVIA was eluted separately from the column packed with bCD-Sepharose using salt gradient and was confirmed by ESI-MS. On using radioactively labeled [3H]1-PP as a substrate in a farnesylation reaction it was seen that prenylated protein product was isolated not only from unreacted protein but also from unreacted prenyl diphosphate in the $\beta$-CD-Sepharose column. $\beta$ CD-Sepharose FPLC upgraded the fraction of prenylated mCherry.Therefore this study proved that prenylated cells were isolated and proteins were purified by affinity chromatography on $\beta$-CDSepharose. This technique is used for lipid-modified protein studies.

\footnotetext{
Affinity chromatography- A protein purification strategy
}

Protein purification is a process essential for many purposes in a biochemical and biological process and many types of protein purification strategies are used for various purposes. The success of affinity chromatography depends on each chromatographic step and hence, optimization of the protocol is done to achieve maximum purification efficiency. Affinity chromatography involves specific interaction between protein and the solid phase (column with specified interaction that will allow the separation of the target molecule. To obtain a pure protein, some parameters like $\mathrm{pH}$, ionic strength, temperature, and dielectric constant should be in balanced form. Equilibration is done with a binding buffer at the initial steps. The sample is prepared at the correct concentration and is loaded in the column as it is a crude sample, wash buffer is added to remove unwanted molecules. The targeted proteins interact with the immobilized proteins in the column which looks like an enzyme-substrate binding, although the interaction can occur through hydrophobic interactions, ionic bonds, hydrogen bonds, and charge transfer. As the protein of interest is separated, elution is done by alteration of $\mathrm{pH}$, ionic strength, or adding a ligand solution for competitive binding in the protein site. The same process is done in immunoaffinity, except for the fact that the immobilized proteins are antibodies here which are purified and immobilized in the first step, followed by usage of immobilized antibodies to identify or purify antigenic proteins. DNA-binding proteins can also be purified by immobilizing a sequence on the column specific to the DNA-binding protein and are eluted afterward by high salt concentration. The purification power of affinity chromatography is often larger than other chromatographic techniques, resulting in several hundred purification factors in a single step. One of the most common ways to immobilize ligands with free amino groups is with Sepharose activated with cyanogen bromide, the adsorption step is often performed with low ionic strength buffers and which 
results in non-selective electrostatic adsorption. Importance should be given to various affinity supports (saturation of the protein) to be applied to the matrix since the possibility of contaminants can occur by non-selective interaction.

\section{Dye affinity chromatography for purification of Bovine Lactoperoxidase from whey}

Bovine lactoperoxidase is a glycoprotein found in milk, saliva, and tears. It plays a major role in the degradation of carcinogens and animal cells peroxidative effects. These proteins are purified from whey, milk using ion-exchange chromatography, yielded between $40-90 \%$ it is then co-purified with another protein called bovine lactoferrin. This study aims to characterize a dye affinity ligand immobilized on a sepharose 6B for direct bLp recovery and purification. Dye sepharose matrix is synthesized using dyes with various colors and is immobilized on sepharose 6B. Then bLp was purified using 3 alternative buffer solutions in the batch process and was also purified in a packed bed column using the Reactive Red 4-Sepharose matrix. The absorbance was measured and the protein was quantified using the Bradford method. Five matrices out of 18 different dye-sepharose showed $90 \%$ absorbance of bLp protein directly from whey without any conditioning, were selected and used for further studies. The absorbance was due to the electrostatic and hydrophobic interaction between the protein and the dye matrix. As the Reactive Red 4-Sepharose matrix showed good performance in all aspects than the other 4 selected matrices, it was characterized using a packed bed column. In batch process adsorption of bLp from pure solution and whey was compared in which the adsorption was faster in the former one. In the case of a packed bed column, some part of bLp was loosely adsorbed to the matrix and was washed during column washes due to the presence of other whey proteins. Due to this problem, high yield and purity of bLp protein were obtained in batch mode compared to packed beds. Processing of whey is difficult, it also requires additional concentration and conditioning for improving the chromatographic performance. This is the reason why a low yield was obtained in a packed bed column. The results also suggest that dye affinity would be a good option for the purification of bLp protein.

\section{An assessment on Affinity Chromatography}

Affinity chromatography is the combination of bio affinity and chromatography, which provides high selectivity, high resolution, and high capacity for the protein. It works mainly based on the interactions between the molecules where the ligand is attached to the solid support, and when a mixture is passed over the column the biomolecules with high binding affinity bounds to the ligand. On washing the column unbound molecules are washed away, and the bound molecules are separated from the support as a result of purification. Various biomolecules such as enzymes can also be purified using this technique. During the olden days, purification methods were based on $\mathrm{pH}$, ionic strength, or temperature, and these conditions are now replaced using affinity chromatography. A higher purification rate is also achieved by using this method. Affinity purification involves 3 steps: a) incubation of a crude sample with affinity support to make sure that the target molecules bind to the immobilized ligand, b)washing away the unbound samples c)elution of target molecule from the ligand. The elute can be monitored if an HPLC support is attached to the affinity column (as an on-line method). Support Matrix which is physically and chemically inert is used for the attachment of ligands which is made up of agarose, cellulose, silica, etc. A spacer arm is used between the matrix and the ligand for effective binding. Monoclonal antibodies are used as a ligand for protein purification as they are more desirable than polyclonal antibodies, another type 
called dye-ligand is also used. Affinity extraction can be done using the On-line and Offline method. Affinity chromatography is used to study proteinprotein interactions, post-translational modifications, and protein degradation, it can also be used for the discovery of biomarkers when reverse-phase affinity chromatography is coupled with mass spectrometry. Pathogens can also be removed by this method. Other types include detection of a direct analyte, Boronate, lectin, immunoaffinity, metal ion, analytical affinity chromatography which differentiate from each other by the stationary phase.

Immobilized metal affinity chromatography for zinc finger protein purification by dual column approach Purification of recombinant proteins is done by immobilized metal affinity chromatography by using zinc fingers as the affinity tag. This technique has a high recovery yield and binding capacity thus making a single-step approach. Zinc finger proteins consist of zinc-binding motifs. An account of the intrinsic property of the zinc fingers to correlate with zinc ions makes it easy to purify without the use of fusion tags. The methods include the expression and purification of zinc finger fusion protein with the IMAC and dual column process. Firstly zinc-finger fusion proteins were recovered through dialysis by removing existing metal ions so that the purity level of protein increased In the dual-column process $\mathrm{Ni}$ (II)-IMAC was chosen as the positive column and $\mathrm{Zn}$ (II)-IMAC as a negative column. E. coli K-12 strain ER2267 was grown and centrifuged to extract the crude cell lysate carrying zinc finger fusion protein and given for dialysis to remove the chelated metal ions. Then metal ion loaded NTA Imac resin was prepared by equilibrating the Ni-NTA resin in a metal ion solution. For the purification process, the dialyzed cell lysate is loaded to the IMAC column with the resin. In the case of dual-column, the cell lysate is first given to the $\mathrm{Zn}$ (II)-IMAC column, and flow from this column is fed into the $\mathrm{Ni}(\mathrm{II})-\mathrm{IMAC}$ column, and protein concentration and purity were analyzed by Bradford method and SDS-PAGE respectively. Optimization results provided that zinc finger fusion protein and unwanted protein adsorption is caused by the coordinate bonding with the chelated $\mathrm{Ni}$ (II) ions by the ionic interactions. Absorption of the proteins was seen reduced except Fe(III). Therefore the adsorption capacity was arranged in the order $\mathrm{Ni}$ (II) $>\mathrm{Cu}$ (II) $>\mathrm{Zn}$ (II) $>\mathrm{Co}$ (II). To reduce the adsorption of unwanted proteins, imidazole was added to the buffer and it was found that $\mathrm{Zn}$ (II) ion showed the lowest adsorption capacity and thus was employed as a negative column in the dual column. On comparing the purification efficiency between the dual and single column, the purity of the eluted fraction was higher in the dual column compared to the other. This paper stated that zinc finger is used as an affinity tag for recombinant protein purification and also proved that the zinc finger proteins are purified without using affinity tags by IMAC, especially for the structural analysis.

\section{Purification of Bovine Serum Albumin by Affinity membrane and Monolith}

Downstream processing of proteins involves affinity capture which is performed through a chromatographic process; this step purely depends on the matrix used. This work involves the binding of BSA on different chromatographic media functionalized with Cibacron Blue F3GA (CB), regeneration of cellulose membrane and polymer monolith, and evaluating it based on the BSA binding capacity and productivity. Membrane chromatography is used for the capturing of antibodies, viruses, DNA fragments, etc. the support material used here is monolith which is obtained from poly(glycidyl methacrylate-co-ethylene dimethacrylate). They have specific areas lower than beads but higher than membranes. The advantage of using monolith and membrane over beads is that connective material's capacity and resolution are independent of flow rate which allows them to work 
at higher flow rates with reduced process time. Dyes that interact with the biomolecules are classified as affinity ligands; one such is Triazine dye is an alternative for the natural ligand. The method includes the preparation of affinity membrane by chemical immobilization and ligand immobilization, followed by monolith functionalization, characterization of chromatographic materials. The experiment was performed with different values of BSA concentration and different values of flow rate. Membranes had the higher CB density, dynamic binding capacity decreased as the flow rate increased, this signifies that in the case of a packed column, low velocity must be used for the capture process. Characterization of resin, membrane, and monolith was conducted and compared with binding capacity and productivity. The preliminary experiments showed that membranes and monoliths performed better than the packed column with a fast purification process and high productivity. The results showed that usage of convective stationary phases will reduce the purification process time, reducing buffer consumption, and avoiding protein degradation.

\section{Silica-derivatized spin columns and 96-well plates for purification of Car9-tagged proteins}

To achieve fast and cheap purification of proteins car9 affinity tag is fused with the $\mathrm{N}$ - and $\mathrm{C}$ - terminal of the proteins. The column is made of silica, it relies on the eluent, L-lysine. On another side borosilicate, a well plate is used for recovering the car9-tagged proteins. Spin column purification along with optimization for the purification was carried on along with assays which include car9. Both Ni-Nta and glutathione agarose resins are costly to purify the GST tagged proteins, so to overcome this silica is used in this study as it is cheap and biocompatible. This study involves a car9 tag for the purification of protein using silica membrane-containing spin columns and a 96well plate. Spin column purification in which the plasmid DNA of E.coli cells was collected as lysates containing tagged proteins and was poured into the column and by elution buffer, the protein was collected and purity was checked using SDS-PAGE. Protein sfGFP-Car9 was expressed and was purified using affinity chromatography and were then loaded onto the silica spin column, the proteins were eluted using Tris-Hcl which had some small concentration of L-lysine and was analyzed by SDS-PAGE. The purified car9 was subjected to dialysis and was cleaved on incubation with the Car9-TEV (plasmid). Through silica, slurry Excised tags, Car9-TEV, and unprocessed Car9-DI were eluted and activity was checked. Cells with different plasmid DNA were grown on the Borosilicate membrane-based 96 well plates and centrifuged to get cell lysate which is then loaded onto the filter plate, aspired to vacuum, and by using the elution buffer the bound proteins were eluted. Purifying Car9-tagged proteins in the silica spin column yielded proteins with $95 \%$ purity as both sfGFP-Car9 and Car9-sfGFP were expressed at a high level in E. coli. Maltose binding protein helps TEV in E Coli, to undergo self-cleavage and yields MBP and HisTEV which is then purified by Ni-NTA affinity chromatography. CAR9 tagged proteins were purified and eluted at the cheap condition using the silica spin column and also with borosilicate well plate using non-toxic reagents. $85 \%$ purity of the protein was obtained using a spin column.

\section{The ionic liquid-based aqueous two-phase system} coupled with a dialysis membrane for the extraction and purification of aloe polysaccharides

The anionic liquid-based aqueous two-phase system was used in this study for the extraction and purification of aloe polysaccharides (APS) and proteins parallelly. APS is extracted by the salt-rich phase and purified using dialysis membrane, on the other side the proteins are extracted by IL rich phase and recycled by using dichloromethane. The ionic liquid-based aqueous two-phase system (ILATPS) is simpler and greener on comparing it with the other 
liquid-liquid extraction techniques. The main force between APS and ATPS is the hydrophilicity interaction. The aloe gel is made up of APS which is responsible for wound healing, anti-inflammation, and immunomodulation properties. When IL and ATPS are used together it has more advantages, which include little emulsion formation, free of volatile organic solvent, quick phase separation, high extraction efficiency, and gentle biocompatible environment. Fresh Aloe leaves were crushed and the juice was filtered and given for centrifugation, the precipitate was collected, and both the APS and protein were simultaneously extracted by a two-phase system where the top phase consists of proteins and the bottom phase consists of APS. APS and protein concentration were analyzed by the Vis spectrophotometer and Bradford method respectively. (NH4)2SO4 and NaH2PO4 were used as the phaseforming salts, because: 1)they possess strong phaseformation ability with IL; 2)have good solubility in aqueous solution; and 3)two salts can form weakly acidic aqueous solutions, which 4)they can't react with $\mathrm{H} 2 \mathrm{SO} 4$ when the determination of APS uses the phenol-H2SO4 method. The effect of temperature was seen in the two-phase extraction method, when temperature increased water was transferred from the top to bottom phase, meanwhile when the IL Rich phase volume decreased the salt-rich phase increased. $\mathrm{pH}$ influenced the extraction efficiency of APS. Most charged proteins can obtain at a low $\mathrm{pH}$ level. A BF4/NaH2PO4 ILATPS coupled with the dialysis membrane was used to extract and purify APS by ethanol 1 precipitation.APS in the salt-rich phase was separated from salts by the dialysis membrane. The purity of APS was checked using TGA.

\section{Avoidance of Dialysis during protein purification.}

Dialysis using membrane is used for the separation and purification of molecules with low weight. In this study acid protease was isolated from Aspergillus species, assays were carried out and dialysis was done.
Following that chromatography was allowed to run and ammonia was quantified. It involves many steps: a)ultrafiltration b)reverse dialysis. The protease is salted out by ammonium sulfate and ammonium sulfate is removed by dialysis tubing. A.Niger was grown and acid protease enzyme was produced from it and filtered through Whatman filter paper and absorbance was measured in $280 \mathrm{~nm}$. Cellulase assay was carried out and absorbance was read at $540 \mathrm{~nm}$. A chromatographic test was done to assess the presence of protease, cellulase, and ammonia. The purification of protein was done by the biurets method leading to a complex color complex presentation. Firstly the reaction copper $[\mathrm{II}]$ reacts with the peptide bond in the protein under alkaline conditions, resulting in their reduction to cuprous [I] ions and the ammonia was quantified. Aspergillus species are low in cost for production and downstream labeling and so it was purified for this study. It is then subjected to precipitation of proteins by salting out methods. The dialysis is carried out using a nitrocellulose membrane. Due to the presence of pores in the membrane sample was lost. A separate ammonium sulfate spin column was used but this showed a low recovery enzyme. Dialysis is not used for the removal of small molecules. Even though dialyzing out ammonium sulfate is broadly utilized during protein purging, it isn't suggested exceptionally for cellulases. Molecular sieving utilizing bio gel-P100 was used rather than dialysis successfully eliminating ammonium sulfate. As practically all organisms are known to have cellulases, alongside different chemicals, generally accessible dialysis layers are probably going to be degraded by the cellulase protein present in the fungal. Henceforth, it is suggested not to use cellulose-based dialysis tubing with fungal enzymes.

\section{Purification of silk fibroin from silkworm by dialysis}


Silk regeneration is inhibited by the dissolution of silk fibroin in a highly concentrated salt solution. The study involves obtaining the silk materials and extracting the silk protein by adding acetone. The extracted protein was then dialyzed, given for desalting, and the recovery is calculated and it was also reported as a novel method which can improve the desalination efficiency of silk protein without causing any harm to its structure. Silk fibroin is a natural biodegradable polymer-based protein extracted from the silkworm. Due to its biocompatibility, it is used for maintaining the morphology of the cell, and has no toxic and irritation effects on the human body. Silk fibroin consists of sericin which is to be removed by degumming. Cocoons were degummed and dissolved in $\mathrm{LiBr}$ solution. The silk protein was extracted by mixing SFLBS with acetone and then treated with deionized water. By rotary evaporation, acetone and $\mathrm{LiBr}$ solution were collected at $50^{\circ} \mathrm{C}$ and $100^{\circ} \mathrm{C}$ respectively. The extracted silk fibroin solutions were dialyzed and checked whether the salt in the solution is completely removed and the molecular weight was checked by SDS-PAGE. . Silk fibroin solution was coated with the PVC membrane to form the Silk fibroin membrane. Salinity test for SF-LBS, ESFS, and ESFS $\times 1$ was carried using dialysis against deionized water. The recovery rate was measured and the structure of silk fibroin membranes was analyzed by IR Spectra and by using the X-ray diffractometer the secondary structure of regenerated silk fibroin was analyzed. The protein extracted from acetone was found completely dissolved in water, uneven surface of the protein surface indicated that protein concentration is high. The salt concentration of SFLBS showed some effects on protein extraction, when the salt concentration was low the protein was denatured during the process. Proteins extracted from acetone affected their stability and translucency. From dialysis, the salt concentration was found to increase in the order $\mathrm{ESFS} \times 1<\mathrm{ESFS}<\mathrm{SF}-\mathrm{LBS}$. The IR results showed that the membrane had $\alpha$-helices and $\beta$-sheet whereas the $\mathrm{X}$-ray diffraction indicated that acetone extraction did not influence the secondary structure of regenerated fibroin membrane. Therefore it was proposed that this is an environment-friendly method where the time was reduced, the stability and the secondary structure of regenerated silk had only minimal changes and thus the silk fibroin was extracted and purified.

\section{Membrane Protein Purification by dialysis through polystyrene adsorbents}

Membrane proteins found in the cell or an organelle are involved in cellular functions such as cell interaction, signal transduction, etc. There was always a constriction for purifying membrane proteins. The methodology involves overexpression and purification of hPLSCR3.The purified fraction consists of inclusion bodies, then these inclusion bodies were solubilized using dialysis against $\mathrm{N}$ Lauryl Sarcosine (NLS).NLS amount was measured using UV-spectrophotometer. On the other hand, the polystyrene beads were washed and saturated with detergent by rotary spinning. For the further purification of hPLSCR3, the chromatography column was filled with Ni-NTA resin, the column was equilibrated with buffer and NLS removed protein. The final elution was treated with imidazole to eliminate unbound proteins, later this imidazole was removed by dialyzing against buffer and the product was analyzed using SDS-PAGE. The eluted protein was estimated using the BCA assay. Liposomes were prepared, in which the protein fraction was reconstituted and after the solubilization step detergents were removed by the beads. The extruded liposomes were labeled with NBD - PE and incubated with EDTA, then tagged with fluorescence and the intensity was measured. Far-UV CD spectra of the buffer and protein solution were recorded by spectropolarimeter. The detergents were removed by 
increasing the incubation period. Compared with the conventional dialysis method beads were able to remove NLS at a $\sim$ tenfold higher rate. The purification didn't show any difference between dialysis and the Bio-Beads method. $\alpha$-helical secondary structure was retained in both cases without any alteration. Dialysis needs a large amount of buffer for removing detergent but the bead-based method needs less quantity of buffer. The buffer is changed until NLS reaches the equilibrium. It was seen that NLS removed in batch mode by Beads produced a reproducible and faster way because it is important to remove the detergents rapidly in case of membrane protein as it might get aggregated. It is concluded that polystyrene-based beads give complete and faster removal of detergent for the purification process. This method is cheap and less laborious.

\section{Isolation of C-peptide from Two-step Ion-exchange Chromatography Combined with Reversed-phase Chromatography for Mass Spectrometric Analysis}

Mass Spectroscopy is one of the most used tools in the analysis of the biochemical entities. But its function is limited to the availability of the samples. This study has tried to eliminate the issue by adopting a 2D technique by combining liquid chromatography with mass spectroscopy. In this study a combination of ion-exchange (IEx) and Reversed-phase (RP) chromatography for the purification of the C-peptide. The usefulness of this approach for isolating the fractions in the desired "pI window" is discussed. This can be used for profiling complex mixtures.

Frozen plasma samples were used for quantification after thawing. Methanol was added at the ratio of 1:4 $(\mathrm{v} / \mathrm{v})$ to the sample and centrifuged. The supernatant was filtered using SepPak C18 disposable cartridges and was then subjected to cation ion-exchange step with HiTrap HP SP cartridges for purification. The content was reduced by $20 \%$ and the ammonium formate altered the $\mathrm{pH}$ to 3.95 . The $\mathrm{pH}$ was then adjusted to 5 and loaded to a Mono $\mathrm{Q}$ column equilibrated with $50 \mathrm{nM}$ ammonium formate ( $\mathrm{pH} 5$ ). An anion exchange was performed by a modular Shimadzu LC system containing two binary pumps. Using a Varian Pursuit C18 column RP-HPLC was performed. A linear gradient of acetonitrile was used for C-peptide isolation. Through cation exchange chromatography the $\mathrm{pI}$ was calculated to be around 3 . It also trapped the majority of the impurities. In contrast the anion exchange chromatography is simpler since the $\mathrm{pI}$ is relatively low. Anion exchanger was found to be advantageous for 2D HPLC separation as it provided an advantage of additional sample concentration. The purification was first done with cation exchanger, followed by anion exchanger and finally RP chromatography and this resulted in isolation of components from a narrow range $\mathrm{pI}$ window. In HPLC the elution was performed with an acidic solution of $\mathrm{pH} \sim 2.5$ and units of $\mathrm{pI}$ window $2.5 \mathrm{pH}$ was eluted and this included $\mathrm{pI}$ of the C-peptide which is approximately 3 . This confirmed the high purification of the sample that was loaded. In the dual pump model when the $\mathrm{pH}$ turned acidic the C-peptide started eluting faster in the cationic exchanger. A linear gradient anionic exchanger was used in the anionic exchanger for the elution.

The study has applied ion-exchange purification for the isolation of a narrow fraction of C-peptide at a selected $\mathrm{pH}$ window. This method is particularly advantageous as it allows the analysis of the analyte at low concentrations. Once the desired product is collected this method can be applied to cover the whole $\mathrm{pH}$ intervals. With some modifications this method can also be used for the profiling of complex mixtures.. In addition to this, this method can also be used as an analogue to isoelectricfocusing for MS.

\section{Production and Purification of Polyclonal Antibody Against $\mathrm{F}(\mathrm{ab})_{2}$ fragment of IgG.}


Polyclonal antibodies are essential components in many biomedical and biochemical researches and are produced naturally in the serum. Polyclonal antibodies can be produced from purified $F\left(a^{\prime}\right)_{2}$ and can be used for animal immunization. In this study IgG from humans is purified and verified in all stages using ion- exchange chromatography and SDS- PAGE respectively. Using the enzyme pepsin the IgG was digested and $\mathrm{F}\left(\mathrm{ab} \mathrm{b}^{\prime}\right)_{2}$ fragment was isolated by gel filtration method. Rabbit was immunised by this fragment to produce polyclonal antibodies and this was investigated using ELISA. The anti- IgG F9ab')2 was further conjugated with fluorescein isothiocyanate and studied further. The production, purification and fluorescein isothiocyanate (FITC) conjugation of rabbit anti-human IgG $\mathrm{F}\left(\mathrm{ab}^{\prime}\right)_{2}$ fragments is focused in the study. A highly specific polyclonal antibody was generated against human IgG $\left.\mathrm{F}(\mathrm{ab})_{2}\right)_{2}$ fragment and characterised.

From diethylaminoethyl (DEAE) ion exchange chromatography method IgG is purified from the human blood serum. The collected sample was then analysed using SDS- PAGE (12\%) under reducing and non- reducing conditions at a neutral $\mathrm{pH}$. Electrophoresis was done using a mini--PROTEAN®. The bands were stained using Coomassie Brilliant Blue G 250 and images. Enzyme digestion was done using human $\operatorname{IgG}$ to give a ratio of 60: $1 \mathrm{mg}$ of pepsin at the $\mathrm{pH}$ 3.20. The digestion was stopped using 0.50 $\mathrm{M}$ sodium hydrogen phosphate, $\mathrm{pH} \sim 8.0$. The purification of $\mathrm{F}(\mathrm{ab})$ was one using gel filtration separation technique with normal saline buffer using saline buffer with $75 \mathrm{mM}$ EDTA. The concentration of the protein was determined by a UV spectrometer at $280 \mathrm{~nm}$. The purity was again checked by SDSPAGE. New Zealand white rabbit was used for immunization and serum preparation. $300 \mu \mathrm{g} / 300 \mu \mathrm{L}$ of $\mathrm{F}(\mathrm{ab})_{2}$ and equal volume of freund's complete adjuvant was first inoculated via intramuscular routes. Second and third inoculation was done on the $21^{\text {st }}$ and $35^{\text {th }}$ day. And the final inoculation was done on the $45^{\text {th }}$ day without the adjuvant. The Ab produced was investigated using ELISA and the total concentration of the protein in the serum was measured by UV spectrophotometer at $280 \mathrm{~nm}$. The serum was then centrifuged and the proteins were precipitated and dialysed against PBS, pH 7.20. The dialysed sample was then applied to DEAE ion- exchange chromatography using $75 \mathrm{mM}$ Tris- $\mathrm{HCl}, \mathrm{pH} 8.10$ as the elution buffer. The collected fraction was then analysed through SDS- PAGE. The Ab precipitate was again dissolved in PBS, pH 7.40 and dialysed against a reaction buffer containing $500 \mathrm{Mm}$ carbonate, $\mathrm{pH}$ 7.40. $1 \mathrm{mg}$ od FICT was dissolved in $1 \mathrm{~mL}$ of dimethyl sulfoxide and added to $\mathrm{Ab}$ to give a ratio of $60 \mu \mathrm{g}$ per $0.50 \mathrm{mg}$ of IGg. The reactivity of the conjugated IgG was assessed using flow cytometry and Cell Quest 3.10 software.

The protein content in $5 \mathrm{~mL}$ of serum was $100 \mathrm{mg}$ and was reduced to $90 \mathrm{mg}$ after salting out and dialysis. The ion- exchange chromatography yielded 38mg of IgG antibody. Through SDS- PAGE the size of the igG band was found to be $150 \mathrm{kDa}$. The gel filtration technique yielded $36 \mathrm{mg}$ of $\left.\mathrm{F}(\mathrm{ab})_{2}\right)_{2}$ fragment. The purity of $\left.\mathrm{F}(\mathrm{ab})_{2}\right)_{2}$ fragment showed a band in 90 $\mathrm{kDa}$ in the following SDS- PAGE. The ELISA method showed that the immunised rabbit's serum showed highest absorbance with $\mathrm{F}\left(\mathrm{ab}^{\prime}\right)_{2}$ at $1 / 128000$ dilution. The ion exchange chromatography resulted in $12 \mathrm{mg}$ of anti- human IgG $\mathrm{F}(\mathrm{ab})_{2} \mathrm{Ab}$. The result of the further reduced SDS-PAGE for defining the purity of polyclonal rabbit anti-human IgG $\mathrm{F}\left(\mathrm{ab}^{\prime}\right) 2$ disclosed a distinct band in $50 \mathrm{kDa}$ and the bands sandwiched between 25 to $30 \mathrm{kDa}$ positions. The comparison of FITC conjugated $\mathrm{Ab}$ and with the ones that were commercially available showed the efficiency of the Ab. The ion- exchange chromatography exhibited high binding capacity and proved to be a cost effective method for the purification of IgG from the serum. The study used ion- exchange 
chromatography to elute polyclonal $\mathrm{Ab}$ by changing the mobile phase. The product purity (95\%), and amount (12mg) of IgG from rabbit serum was higher when compared to previous studies. Anti-IgG F(ab') PA that interacted with human $\operatorname{IgG} F\left(a b^{\prime}\right)_{2}$ fragments exhibited high specificity and affinity. This can be a useful tool in the biomedical and biochemical researches and immunoassays. The purified IgG $F\left(a b^{\prime}\right) 2$ is valid for conjugation with enzymes and radiolabels, immunoelectrophoresis, immunodiffusion, immunohistochemistry and flow cytometric tests and as immunoadsorbant for attachment to solid support.

\section{Purification of an Antioxidant Protein P4-1 from fertilized eggs and its characterization}

Free radicals are potent damaging molecules that can be formed in the tissue in several metabolic pathways. If not eliminated they can lead to several chronic diseased conditions. Antioxidants are necessary for the scavenging of free radicals. Fertilized egg protein has an abundance of naturally occurring antioxidants which can be used in the food and cosmetic industries. In this study an antioxidant P4- 1 was isolated from 15 days old fertilised hen eggs and purified using chromatographic methods. The characterisation was done using SDS- PAGE, LC- MS and many other biochemical assays. There are many synthetic antioxidants available such as butylated hydroxyanisole (BHA), propyl gallate (PG), and butylated hydroxytoluene (BHT) but they may cause liver damage and carcinogenesis. Thus there is a high demand for natural antioxidants. The study has used fertilized hen eggs for the isolation of a novel and natural antioxidants and its antioxidant activities and biological properties were evaluated.

15 days old fertilized hen eggs were used for the study. It was then mixed and cold centrifuged. Further it was freeze dried using FD- 1B- 5D freeze drier at $50^{\circ} \mathrm{C}$ for 24 hours and the protein was extracted using $0.2 \mathrm{M}$ sodium phosphate buffer solution, $\mathrm{pH} 7(1: 10 \mathrm{w} / \mathrm{v}$ ratio). This was further centrifuged and the supernatant was subjected to salting out using $80 \%$ ammonium sulfate at $4^{\circ} \mathrm{C}$ for 30 minutes and followed by centrifugation. The sample was then desalted and dialysed and concentrated to obtain the crude protein. The contents of the crude mixture were determined using Kjeldahl method. To characterise the radical- scavenging activity of the a $\mathrm{DPPH}$ radical-scavenging activity (RSA) assay was performed according to the method by Je. Similarly, $\mathrm{O}_{2}-$ radical and $\mathrm{OH}$ radical- scavenging activity assays were carried out for the extracted sample proteins. The protein was dissolved in a $0.02 \mathrm{M}$ phosphate buffer, $\mathrm{pH} 6.8$ and cold centrifuged. The supernatant was filtered and loaded to a DEAE Cellulose FF anion exchange column. It was further loaded into $\triangle \mathrm{KTA}$ Purifier Plus chromatography system and equilibrated and washed out with a flow rate of $1 \mathrm{~mL} / \mathrm{min}$. The elution peaks were detected at $280 \mathrm{~nm}$. This was followed by Gel- filtration chromatography by Sephadex g-100 gel was performed further to extract the P4- 1 protein by the method described by Ahmed et al. The molecular weight was analysed through SDS- PAGE (12\% \& 5\%). The bands were stained with Coomassie brilliant blue R-250 and the standard proteins used had the molecular masses ranging from 14.4- $94.0 \mathrm{kDa}$.Further the bands were excised and identified through analysis using ProteomeX-LTQ 2D-LC-MS system. The amino acid composition analysis of the P4-1 was done through an L8900 Automatic Amino Acid Analyser and its thermal transitions were identified through a TA Q200-DSC thermal analyser. The assays were performed in different temperatures (30, 40, 50, 60, 70, 80, 90 and $\left.100^{\circ} \mathrm{C}\right)$ and $\mathrm{pH}(3,4,5,6,7,8,9$ and 10$)$ and incubated at a constant time interval of 30 minutes.

Through the Kjeldahl method the nitrogen content in the sample was found to be $89 \%$. The $\mathrm{P} 4$ peak from the ion exchange chromatography showed a higher antioxidant activity in the oxidation resistance test. 
The percentages of scavenged $\mathrm{DPPH}, \mathrm{OH}$ and $\mathrm{O}_{2}-$ were found to be $56.77 \pm 0.86 \%, 66.37 \pm 1.33 \%$ and $55 \pm 1.12 \%$ respectively. The gel filtration elution also showed a single peak of P4- 1 . The molecular weight of the antioxidant P4- 1 from SDS- PAGE was found to be $45 \mathrm{kDa}$. Through liquid chromatography- mass spectroscopy it was identified that P4- 1 protein contained 386 amino acids and the molecular mass was $42,854.5$ and had a pI of 5.07. The main amino acid compositions were glutamic acid (24.17\%), aspartate (17.19\%), and tyrosine (15.69\%). The antioxidant showed optimum activity in the temperature range of $30-50^{\circ} \mathrm{C}$ at lower $\mathrm{pH}$ conditions. The antioxidant denatured at $57.16^{\circ} \mathrm{C}$. During the incubation of a fertilized egg the antioxidant in it considerably increases to protect the developing embryo from the free- radicals damage. In this study, the derived proteins from the fertilized hen eggs exhibited antioxidant activity. Thus, it is proposed that a fertilized egg can be a new natural source for antioxidant proteins. Further studies are essential to understand the mechanism of its activity and to assess it's prospective in the food industry.

\section{Purification Strategy for Proteomic Profiling of $\mathrm{HDL}_{2 / 3}$}

One of the leading causes of death worldwide is cardiovascular diseases. This calls for suitable predictive disease biomarkers. Lipoprotein- specific biomarkers can be used to indicate an individual's susceptibility to developing such disease. Highdensity lipoprotein has been previously reported to have about 90 proteins using conventional purification techniques. One major issue of global protein characterisation is contamination. HDL is rich in proteins and is involved in the acute-phase response, complement activation, proteolysis, immunity and many other metabolic pathways. In this study, a newly refined purification strategy has been developed to isolate HDL. This strategy is more reliable for quantification as it isolates HDL by density first and then purified by size. The refined method is proposed to be adopted as the standard proteomic assessment of HDL2/3. The blood samples collected from healthy control subjects were taken with a signed informed consent form. All procedures were carried out with approved guidelines and all study procedures and protocols were reviewed and approved by the ethics committee of the Medical University of Graz, Austria. Through two-step density gradient ultracentrifugation or dextran sulfate precipitation method HDL was isolated from serum. This was followed by size exclusion chromatography using an NGC QUEST FPLC System with Superdex 200 Increase 10/300 column was used. 10mM Tris, $150 \mathrm{mM} \mathrm{NaCl}, \mathrm{pH} 7.4$ was used as a running buffer. A constant flow rate of $0.5 \mathrm{ml} / \mathrm{min}$ was set after $18 \mathrm{~min}$ with $0.25 \mathrm{ml}$ per fraction. 3,3'Dithiobis(sulfosuccinimidyl propionate (DTSSP) and PEG12-SPDP crosslinker were used to cross-linking of the HDL proteins. This was flowed by antibody coupling and immunoprecipitation using a commercially available kit (Dynabeads Co-IP Kit, Nr.:14321D, Life Technologies). The procedure was carried out according to the manufacturer's instructions. Isolated HDL was separated using gradient electrophoresis under non reducing and nondenaturing conditions for native gel electrophoresis. The gels were stained overnight by Coomassie Brilliant Blue G- 250. Molecular marker containing bovine serum albumin $(7.1 \mathrm{~nm})$, lactate dehydrogenase $(8.2 \mathrm{~nm})$, B-phycoerythrin (10.5nm, apoferritin band $1(12.2 \mathrm{~nm})$ and apoferritin band 2 $(18.0 \mathrm{~nm})$ was used to determine the size of HDL. Bands were excised for proteomic analysis. Isolated HDL was separated by SDS- PAGE under reducing and denaturing conditions for denaturing electrophoresis. A constant voltage of $150 \mathrm{~V}$ was used for 120 minutes in SDS. Molecular weight markers were used for size determination. Both native and SDS- PAGE gels were transferred to polyvinylidene 
difluoride membranes with $100 \mathrm{~V}$ for 60 or 90 minutes respectively at $4^{\circ} \mathrm{C}$ for blotting. The membranes were probed with primary antibodies diluted in $5 \%$ milk at $4 \mathrm{C}$ overnight ( appo A-I, apoCI, SAA, apoA- IV, $\alpha-1-$ antitrypsin. Membranes were washed and incubated for 2 hours at ambient temperature with secondary HRP- conjugated antibodies and developed. The detection was performed using a Chemidoc Touch imaging system. Further LC-MS/ MS measurements were taken using appropriate techniques The HDL proteins were successfully isolated in the study. The proteomic analysis by LC-MS/ MS determined a high amount of proteins in one sample. The HDL isolated only by ultracentrifugation contained 26 different proteins. Further, the purification with native gel electrophoresis resulted in a decrease of $\mathrm{HDL}_{2 / 3}$ protein to 19. The main constitutions were apoA- I and apoA- II. The proteomic analysis also revealed that many proteins which have recently been described to be associated with HDL2/3. This included $\alpha$-1-antitrypsin, $\alpha-2$-HS-glycoprotein, serotransferrin, apoA-IV and are exclusively associated with the fraction containing lipid-poor apoA-I, HSA and other contaminants. Further, the study indicated that HDL2 composed of 13 proteins and HDL3 composed of 10 proteins. HDL2 had a higher content of apoA-I and apoE and HDL3 was rich in apoA-II and paraoxonase 1. The immunoblotting and cross-linking experiments confirmed the distinct separation of proteins. The given proposed method is rapid, simple and highly efficient when compared to conventional techniques and can have a large impact on standard proteomic assessment for HDL2/3. Through this study, it is hoped to discover lipoprotein- specific biomarkers which can be helpful for the early diagnosis of the disease.

Isolation, Purification and Characterization of Enzyme Xylanase Produced by a Species if Bacillus Species
Xylanase is an enzyme which plays a great role in industrial application, including the paper industry. A new strain of Bacillus bacteria was found and isolated. Many species of Bacillus and fungi secrete a considerable amount of extracellular xylanase. The study has described a simple but both cost and yield efficient method for the industrial production of xylanase using agricultural residues and fermentation for the production of microorganisms that produces extracellular xylanase. The study for the first time characterises extracellular alkalothermophilic xylanase produced by a species of Bacillus which is similar to Bacillus arseniciselenatis DSM 15340 grown in solid state fermentation. The bacteria were collected and screened from the soil sample and was identified through 16 sRNA sequencing and then isolated. Wheat barn soaked with moistened basal salt solution was fermented with the bacteria for 48 hours, it was then added to $50 \mathrm{nM}$ phosphate buffer to extract xylanase through centrifugation at $5000 \mathrm{~g}$ at 4 $\mathrm{C}$ for 10 minutes and filtered through Whatman No. 1 filter paper. The filtrate had the crude enzyme extract. The activity of the enzyme was measured according to Bailey et al and the cellulase activity was measured according to Ghose with some modifications. Similarly $1,4-\beta-$ xylosidase activity was measured according to Lachke and finally the protein content was measured according to Lowry's method at 280 $\mathrm{nm}$. The protein was finally precipitated by the process of salting out using ammonium sulfate and centrifugation at $10000 \mathrm{~g}$ for 10 minutes. This was followed by dialysis using cellulose tubing. The dialysed enzyme was then loaded to DEAE cellulose column for anion exchange chromatography. The protein was eluted using $\mathrm{NaCl}$ gradient and 50 fractions of $5 \mathrm{~mL}$ each was collected at a flow rate of 1 $\mathrm{mL} / \mathrm{min}$. This was continued by SDS- PAGE using $12.5 \%$ acrylamide gel according to Laemmli method, and the bands were stained with coomassie brilliant blue R-250. The protein markers that were used ranged from $14.4 \mathrm{kDa}$ to $94.0 \mathrm{kDa}$. The substrate 
specificity of the xylanase was tested using $1 \%$ xylan, cellobiose, starch, carboxymethyl cellulose (CMC), and p-nitrophenyl xylopyranoside and Avicel as substrates. Kinetic parameters were studied using the linear regression method of Lineweaver and Burk, the hydrolysis product of the xylanase was found using thin layer chromatography. The enzyme activity was tested by varying the reaction temperature $\left(30-80^{\circ} \mathrm{C}\right)$. Similarly the activity was also tested at different $\mathrm{pH}$ (6.0- 11.0)

The isolation yielded 25 bacterial strains and was identified on the basis of their morphological and biochemical characteristics. Xylanase production by this bacterium was found to be maximum at the temperature of $45^{\circ} \mathrm{C}$ at the $\mathrm{pH}$ of 8.0. The yield was $910.49 \mathrm{U} / \mathrm{g}$ of dry substance that was cellulose free. The purified Xylanase fraction from DEAE ion exchange chromatography showed maximum in the $19^{\text {th }}$ to $25^{\text {th }}$ fraction. This fraction expressed a specific activity of $299.25 \mathrm{U} / \mathrm{mg}$. From SDS- PAGE the molecular was found to be $\sim 29 \mathrm{kDa}$. Xylanase was found to be active on birchwood xylan, little active on p-nitrophenyl xylopyranoside but not on Avicel, $\mathrm{CMC}$, cellobiose, and starch. The $\mathrm{Km}$ and $\mathrm{V}_{\max }$ values of xylanase were measured to be $5.26 \mathrm{mg} / \mathrm{mL}$ and $277.7 \mu \mathrm{mol} / \mathrm{min} / \mathrm{mg}$ respectively. Analysis of hydrolytic products also showed that Xylanase mainly cleaved xylooligosaccharides. The optimum temperature and $\mathrm{pH}$ of the enzyme was observed as $50^{\circ} \mathrm{C}$ and 8.0 respectively. The study designed an efficient and cost effective method to effectively produce a cellulose free xylanase on a solid medium using the bacterium strain Bacillus arseniciselenatis DSM 15340 like Bacillus strain. The result showed homogeneity and high yield. This method can be used for the large scale production of xylanase for industrial purposes.

\section{Purification of Tropomyosin, Paramyosin, Actin, Tubulin, Troponin and Kinases}

$\mathrm{P}$-aminobenzamidine ( $\mathrm{p}-\mathrm{ABA})$ is used as a ligand in the purification of many serine proteases. It also can bind $\mathrm{Ca} 2+$ binding proteins. During protein purification $\mathrm{p}-\mathrm{ABA}$ is widely used to inhibit proteases, but here it is used in columns to purify non-protease proteins. In this research first, the proteases that were not of interest were inactivated using protease inhibitors. Second, Ca2+ was used to remove calciumdependent proteins. To study the kinetics of these proteases a spectral probe, a synthetic inhibitor of serine proteases $\mathrm{p}$ - aminobezamidine ( $\mathrm{p}-\mathrm{ABA}$ ) is used. This study demonstrates novel applications of $\mathrm{p}-\mathrm{ABA}$ as a ligand in purification processes. Using mass spectrometry analysis along with a proteomic approach based on one and two-dimensional gel electrophoresis, proteins were identified and purified. Lepidoglyphus destructor, Tyroborus lini, Dermatophagoides farinae, Acarus siro, Tyrophagus putrescentiae, Blomia tropicalis, Glycyphagus domesticus and Aleuroglyphus ovatus were the sources of mite proteins. Cockroach and rabbit, O. cuniculus, thigh muscles were collected. $0.1 \mathrm{~g}$ of samples were homogenised three times using sterilized glass Potter-Elvehjem homogenizer with 1 $\mathrm{ml}$ of cold binding buffer and 2o $\mu \mathrm{L}$ of protease inhibitor mix. Homogenised samples were cooled on ice for 20 minutes. Half the volume of the extraction buffer was added and homogenization three more times. The supernatant was then transferred to centrifuge tubes and cold centrifuged in a MR 23i centrifuge. The supernatant was filtered through a $0.45 \mu \mathrm{m}$ regenerated cellulose filter. The $\mathrm{p}-\mathrm{ABA}$ was eluted and equilibrated with the binding buffer in twelve column volumes. The filtrate was then loaded dropwise into the columns and incubated at room temperature for 20 minutes at 4 . The column was cleaned using 20 volumes of binding buffer and twelve column volumes of elution buffer was used to elute the purified protein. It was then cleaned using a PD MidiTrap G-25 and the content was measured using Bradford reagent. Calcium-dependent proteins 
were removed first by using $0.5 \mathrm{M}$ solution of $\mathrm{CaCl} 2$ in $0.02 \mathrm{M}$ Tris- $\mathrm{HCl}$ and the above steps were continued. The separation was carried out using the manufacturer's instructions (Sigma Aldrich) using SDS- PAGE. The proteins were diluted in two different sample buffers one with and the other without the boiling step for electrophoresis respectively. Voltage was kept constant in Ruby electrophoresis instrument during electrophoresis and the gel was fixed for two hours in a fixing solution and stained with $0.02 \%$ PhastGelTM Blue R. Destaining of the gel was done using a fixing solution. For separation Isoelectricfocusing was performed using Ettan IPGPhor 3 instrument. It was done using immobiline dry strips with a range of $\mathrm{pH} 3-10$ and a DeStreak Rehydration solution was used for active rehydration. The separation program was: 1) Step, 30 V, 10H; 2) Step 500 V, 500 Vh; 3) Grad 1000 V, 800 Vh; 4) Grad 6000 V, 15000 Vh; 5) Step 6000 V, 16000 Vh. This was run for 19 hours and immediately followed by equilibrating the strips with an equilibration buffer containing DTT and then again equilibrating it with a buffer containing IAA. The strips were placed on a gel and fixed with $1 \%$ agarose. The voltage was kept constant at $30 \mathrm{~V}$ the electrophoresis was run for $50 \mathrm{~min}$, then at a constant voltage of $300 \mathrm{~V}$, the proteins were separated under cooling. The protein spots were cut from the gel and analysed using Mass Spectrometry and MASCOT software. The data were further compared to the other databases. The purification yielded $3 \mathrm{mg}$ of purified protein from $2 \mathrm{~mL}$ extracts. Oryctogalus cuniculus muscle yielded approximately $4.5 \mathrm{mg}$ of protein. The purification yielded mostly tropomyosin and paramyosin from the crude mite extracts. Two bands of allergen Lep d10 and another two bands opf allergen Der f11 was identified in L. destructor. Der f10 and Der p11 were identified in T. lini. The results indicated that mite tropomyosin is monomeric or dimeric. The SDS-PAGE also confirmed the efficiency of the method. Actin was identified through SDS-
PAGE. The proteins that were identified further were tubulin, troponin and kinases. A p-ABA ligand helped in the purification of proteins with variable specificity. The objective was to purify the protease but no protease was purified. For the first time, the monomeric and tetrameric forms of the tropomyosin and the monomeric and dimeric form of paramyosin was shown. The removal of calcium-dependent proteins made it possible to obtain calcium-dependent and calcium-independent proteins separately. The ability of SDS- PAGE and 2D electrophoresis to purify and separate protein samples was well demonstrated. This method can be applied in many scientific branches and medicinal applications.

\section{About Gel Filtration Chromatography Of Proteins}

Construction of A Standard Curve for A Gel filtration Column with A Separation Range Of 5-250 Kd Is Been Described Over Here. The Size of a Protein Species Stable in A Buffer Containing Tris-Hcl, Nacl, And DTT Is Determined and Modifications May Be Made to The Buffer to Accommodate the Protein of Interest and The Separation Range of The Column.The Eluted Proteins Are More Dilute Than the Original Sample and Dilution Increases If the Protein Elutes at Larger Elution Volumes. By Increasing The Circumference of The Column A Larger Volume of Sample Can Be Loaded onto The Column. Use Care to Pack the Beads Uniformly. The Elution of Different Molecular Weight Species Will Be Affected If There Are Differences in Bead Density Along the Length of The Column. Purification Of GST-Tagged Proteins, Immunoaffinity Purification of Proteins, Strep-Tagged Protein Purification, Proteolytic Affinity Tag Cleavage Are More Ideally Suited for A First Purification Step. One May Concentrate the Sample Further or Use A Longer Column If There Is Not A Reasonable Amount of Separation Between Species. Experiment Should Be Performed Using an FPLC System Capable of Monitoring the UV Absorbance of The Protein(S) Of 
Interest and A Fraction Collector. A Reasonably Pure Protein Sample ( $>90 \%$ Pure) For Characterization by Gel Filtration Through Another Chromatography Method, Preferably Ion Exchange Chromatography Is Been Obtained.

\section{Consequences of Bed Compression on Protein} Uncoupling Via Gel Filtration Chromatography at Bench and Pilot Scale

The Poorly Packed Chromatography Columns Reduces A Lot to The Column Efficiency and Produce Broader Peaks. Controlled Bed Compression Were There as A Useful Approach for Solving This Problem. Here the Relationship Between Column Efficiency and Resolution of Protein Separation Are Examined When Preparative Chromatography Media Were Compressed Using Mechanical and Hydrodynamic Methods. Sepharose CL-6B, An Agarose Based Size Exclusion Media Was Examined at Bench and Pilot Scale.It Has Been Shown That A Compacted Region Near The Base Of Column Forms When Hydrodynamic Compression Is Used, Where Pressure Will Be The Greatest, Also Showed That The Sepharose CL-6B Achieved Improved Asymmetry And Reduced Plate Number At 0.02 Compression Factor Via Hydrodynamic Multiple Incremental Compression Steps; However, The Column Efficiency Declined As Further Pressure Was Applied Due To The Flow Of Buffer. Mechanical Compression Gave Better Column Efficiency, The Impact of Mechanical Compression on Asymmetry and Reduced Plate Height Was Examined Using BSA As A Model Protein. The Reduced Plate Height Improved at Increased Levels of Mechanical Compression. The Improvement Doubled as The Compression Factor Increased From 0.0 To 0.15. Porosity Moved from About 0.4 At No Compression To 0.3 At A Compression Factor of 0.15 With Mechanical Compression. A Porosity Of 0.4.These Results Indicate That for Size Exclusion Separations the Performance of a Given Protein Separation Can Be
Improved by Operating Beds Under Mechanically Compressed Conditions Compared with Hydrodynamic Compression At $30 \mathrm{Cm} \mathrm{H}-1$. This Study Showed The Impact On Column Efficiency When Applying Hydrodynamic And Mechanical Compression To Beds Formed From Sepharose CL-6B, Showed Better Asymmetry And Reduced Plate Height With Increasing Levels Of Mechanical Compression, Regardless Of How This Was Applied (One Step Or Multiple Incremental Steps).

\section{Variation in The Result of DEAE Negative Mode Chromatography and Gel-Filtration Chromatography on The Charge Status of Helicobacter Pylori Neutrophil-Activating Protein}

Helicobacter Pylori Neutrophil-Activating Protein (HP-NAP) Is Involved in H. Pylori-Associated Gastric Inflammation And HP-NAP Is Also A Vaccine Candidate, A Possible Drug Target, And A Potential Diagnostic Marker for H. Pylori-Associated Diseases. A Minimal Amount Of HP-NAP Was Detected in The Elution Fraction of DEAE Sepharose Resin at Ph 8.5. The Surface Charge of The Purified HP-NAP Was Neutral at Ph 7.0 To 8.0 And Was Either Neutral or Slightly Negative at $\mathrm{Ph} 8.5$ And 9.0. However, Recombinant HP-NAP Purified from Gel-Filtration Chromatography Was Able to Bind to DEAE Sepharose Resin at $\mathrm{Ph}$ 7.0 To 9.0 And DEAE Sephadex Resin at $\mathrm{Ph}$ 7.0.We Found That Recombinant HPNAP Bound to DEAE Anion-Exchange Resins at $\mathrm{Ph}$ 7.0 But Not at $\mathrm{Ph} 8.0$ During Purification At $4{ }^{\circ} \mathrm{C}$ from Either E. Coli or B. Subtilis. This Result Is Unexpected Since the Surface Charge Of HP-NAP Should Be More Negative at $\mathrm{Ph}$ 8.0 Than at $\mathrm{Ph}$ 7.0. The Recombinant HP-NAP Expressed in E. Coli Was Subjected to Batch Chromatography Using DEAE Sepharose And DEAE Sephadex Resins Under These Conditions. At $\mathrm{Ph}$ 8.5, The Least Amount of Recombinant HP-NAP Was Detected in The Elution Fraction Whereas A Greater Amount Of HP-NAP Was Present in The Unbound and Wash Fractions. 
For DEAE Sephadex Resin, More Than Half of The Recombinant HP-NAP Was Present in The Elution Fraction at $\mathrm{Ph}$ 7.0. A Much Higher Binding Ability Of HP-NAP to DEAE Sepharose Resin Than to DEAE Sephadex Resin Was Observed Especially at $\mathrm{Ph}$ 9.0. The Purification of Recombinant HP-NAP with DEAE Anion-Exchange Resin Was Investigated at $\mathrm{Ph}$ 7.0 To 9.0 At $25^{\circ} \mathrm{C}$. In the Purification with DEAE Sepharose Resin, HP-NAP Was Detected in The Elution Fraction at $\mathrm{Ph}$ 7.0, 7.5, 8.0 And 9.0, But at $\mathrm{Ph}$ 8.5, HP-NAP Was Least Detected. The Purification with DEAE Sephadex Resin, HP-NAP Was Detected in The Elution Fractions Only at Ph 7.0 And 8.0. Protein Retention On The Resin Is The Result Of The Electrostatic Interactions Contributed By The Net Charge, Charge Density, And Surface Charge Distribution Of The Protein, The Overall Charge And Charge Density Of The Resin, And The Counter Ion Concentration And Ionic Strength Of The Mobile Phase.The Surface Charge Distribution of Recombinant HP-NAP and The Overall Net Charge of DEAE Resin Are the Main Factors Affecting the Purification Of HP-NAP by DEAE Negative Mode Chromatography. Recombinant HP-NAP with Different Charge Status Is Differentially Purified by DEAE Ion-Exchange Negative Mode Chromatography and Gel-Filtration Chromatography. Only Negatively Charged HP-NAP Is Retained from Gel-Filtration Chromatography.

\section{Methods \& Operating Conditions for Gel-Filtration Chromatography}

It Describes the Basis of The Method, The Selection of Suitable Operating Conditions, And Contrasts Typical Matrix Types. Applications of The Technique Are Described, With References to The Scientific Literature.Various Factors Should Be Considered When Designing A Gel- Filtration System. These Include: (1) Matrix Choice, (2) Sample Size and ConCentration, (3) Column Parameters, (4) Choice of Eluent, (5) Effect of Flow Rate , And (6) Column
Cleaning and Storage.Gel-Filtration Matrices Consist of Porous Beads Composed of Cross-Linked Polyacrylamide ,Agarose, Dextran Are Supplied Either in Suspended Form or As Dried Powders. Silica Matrices Have Good Rigidity (Making Them Suitable for High- Pressure Fast Flow-Rate Systems) But Have Hydrophobic Surfaces and Are Unstable at $\mathrm{Ph}>8$. Weaker Polymeric Resins May Compress Under Pressure and Flow, A Drawback That Limits the Extent to Which the Particle Size Can Be Reduced for Chromatographic Applications. The High Mechanical Strength of Beh Particles Enables A Reduction in Particle Size To $1.7 \mathrm{Mm}$, Providing Significant Improvements in Chromatographic Efficiency.Gel Filtration Remains A Popular Separation Method Due to Its Versatility, The Wide Range of Matrices Commercially Available and The Mild Conditions of Operation. This Article Has Given the Reader Some Grasp of The Technique's Wide Range of Applications and How to Choose Appropriate Conditions for Its Gainful Use.

\section{Differentiation Of Germicide Peptide Refining Via Free-Flow Electrophoresis and Gel Filtration Chromatography}

Antimicrobial Peptides (Amps) Are Usually Small and Cationic Biomolecules with Broad-Spectrum Antimicrobial Activities Against Pathogens Which After Purification from Complex Samples Is Essential to Study Their Physiochemical Properties. In This Work, Free-Flow Zone Electrophoresis (FFZE) Was Utilized to Purify Antimicrobial Peptides from Yeast Fermentation Broth and Gel Filtration Chromatography (GFC) Was Conducted for Comparison. When the Carrier Buffer $\mathrm{Ph} 7.0$ Was Used, The Majority of Small Molecular Mass Proteins Was Slightly Deflected and Mainly Entered into the 8th, 9th, And 10th Outlets. At the Same Time, Some Proteins Including Minute Small Molecular Mass Proteins Hardly Deflected and Other Proteins Whose Molecular Mass Was Between 49 K Da And 62 K Da 
Moved to The Anode Which Results in A Good Separation. This Group of Proteins Might Be Either Neutral or Anionic. More Proteins Started to Migrate to The Cathode.After the Approximate Molecular Mass of The Peptides Was Determined. Single Band with A P I Of 7.8 In Both Fractions, Implying That the Two Peptides Have the Same P I. These Two Peptides Have the Same P I With Similar Molecular Mass, FFZE And GFC Might Not Be Competent to Separate Them Because They Always Appeared in The Fractions in Pair.The Optimized Separation Condition, The Target Amps Deflected Fast to The Cathode End of The Separation Chamber with Little Band Broadening, Causing A Distinguished Separation from Other Proteins, The Harvested Amps Retained Strong Antimicrobial Activity. It Had A Lower Purity Than GFC, The FFZE Method Has Higher Recovery Rate Than GFC. Improvement of The Capacity of FFZE In the Separation of Functional Small Peptides. Due to The Merits of High Throughput, Minimum Dilution and Good Reproducibility, FFZE Should Be A Competitive Alternative Method to Continuously Purify Amps from The Complex Fermentation Broth.

\section{Purification \& Portrayal Of Alkaline Protease With New Effects From Bacillus Cereus Strain S8}

Proteases Are The Hydrolytic Enzymes Which Helps Applications In Pharmaceutical And Industrial Sector. An Alkaline Serine Protease Produced By Bacillus Cereus Strain S8 (MTCC NO 11901) Was Being Purified And Characterized., It Was Being Purified By Ammonium Sulphate Precipitation (50\%), Ion Exchange (DEAE-Cellulose) And Gel Filtration (Sephadex G-100) Chromatography. It Obtained A Result Of Purification Of The Protein With Specific Activity Of 300U/Mg Protein And With Purification Fold 17.04 .The Molecular Weight Of The Purified Protease Was Obtained By Using SDS-PAGE Under Non-Reducing (71 Kda) And Reducing Conditions (35 Kda And 22 Kda). The Enzyme Existed As Dimer In
Its Native State. The Molecular Weight Of The Protease (22 Kda) Was Also Determined By Gel Filtration (Sephadex G-200) Chromatography And It Was Calculated As 21.8 Kda. Exhibits A Stability In The Temperature Range $50-75^{\circ} \mathrm{C}$ In Presence Of Calcium .The Alkaline Protease Was Completely Inhibited By PMSF, A Serine Protease Inhibitor And TLCK, Which Is A Trypsin Inhibitor. The Protease Activity Was Enhanced By The Addition Of Xylene, Ethyl Ether, Toluene, Acetonitrile And DMSO, Whereas There Was Decrease In Enzyme Activity Observed With Hexane, Isopropanol ,Methanol, Ethanol, Butanol And Benzene Respectively . From Here We Found Out That The Purified Bibirus CAS 7 Was Was Active Over Wide Range Of Ph Between 5.0 And 12.0 And Optimum Being At Ph 9.0, Even An Enzyme From Bacillus Subtilis DR8806, With Highest Activity At $45^{\circ} \mathrm{C}$,It Was Reported That The Positive Effects With Co2+ And Ca2+ On Protease Rblap From Bacillus Lehesis While Hg2+ Completely Inhibited Rblap.This Study Reveals That The Protease From The Bacillus Cereus Strain S8 With Lower Kм Value Of Protease Reflects A Stronger Binding Affinity Of This Protease To Substrate.The Kinetic Studies Of Alkaline Protease From The Bacillus Cereus Strain S8 Revealed That Lower Kм Value Of Protease Reflects A Stronger Binding Affinity Of This Protease To Substrate.The $\mathrm{K}_{\mathrm{m}}$ And $\mathrm{V}_{\max }$ Were Decided Or Thermostable Protease From Bacillus Halodurans JB 99 By At $70{ }^{\circ} \mathrm{C}$ And Ph 11.0 For Concentrations Ranging Between 0.5 And $7.5 \mathrm{Mg} / \mathrm{Ml}$ Of Casein. All This Results Were An Increase In Specific Activity Of Protease Which Were Obtained After The Ammonium Sulphate Precipitation, Ion Exchange And Gel Filtration Chromatography. The Purified Protease Was Further Characterized By Electrophoretic And Matrix Assisted Laser Desorption Ionization/Mass Spectroscopy (MALDI/MS) Analysis And Found That Molecular Weight Of The Protease Was $23.3 \mathrm{Kda}$. 
Sculpting the Outcome of temperature Via gelfiltration chromatographic for protein Separation

By Using The Fast Fourier Transform Method A Mechanistic Model for Chromatography Was Taken and The Solution to Its Laplace Transfer Function Was Obtained. The Effect of Temperature in Gel Filtration Liquid Chromatography Was Investigated by Using Previously Developed Correlations for Modelling Diffusion, Both in Solution and Intraparticle, And Estimating the Mass Transfer Coefficient. By Gel Filtration Chromatography , A System of Bovine Serum Albumin and Phenylalanine Separated.A Model That Accurately Accounts for The Temperature Effects on Physical Parameters and Uses It in A Predictive Manner to Describe the Column Operation Is Presented in This Paper. The Results Are Dis-Played and The Peaks Become Sharper at The Elevated Temperature; However the Overall Retention Time Does Not Change Significantly. The Peak Shape of The Dextran Peak Changes at Different Temperatures. For the Particle Radius Of $25 \mathrm{Mm}$, The Chromatograms Peaks Are Sharper When Compared to The Previous Results. At the Largest Particle Radius Of $70 \mathrm{Mm}$, The Chromatograms Here Had the Largest width Of Any Simulation in This Study, The Phenylalanine, Which Is Much Smaller Relative to The Other Solutes, Has More of The Intraparticle Void Space Accessible, Which Is Increases the OverAll Residence Time Within the Column. Bovine Serum Albumin Partially Enters the Intraparticle Void Space, Therefore Elutes Faster in. Decreasing Particle Size Enables More Volume for The Retention of The Smaller Solutes. This Becomes More Favorable at Higher Temperature as Solutes Remain Localized Within A Certain Volume of The Column, Which Is Demonstrated by The Minimized Peak Spreading and Increase in Resolution. The Peak Spreading Was Higher Than the Other Two Analytes Which Points at The Fact That the Physical Phenomenon That Governs the Solute Flow in The Column Is
Fundamentally Different from Either the Bsa Or Phenylalanine. Blue Dextran Does Not Enter the Adsorbent Particle and Bypasses the Gel Completely by Convection, So the Accessible Intraparticle Void Volume Does Not Play Any Role in Its Elution. Therefore the Large Molecules Move by Convection and The Smaller Molecules Are Slowed Down by As They Diffuse Inside the Gel Particles. The Chromatograms at Elevated Temperatures Were Sharper and Allowed for Better Resolution of The Components. The Best Resolution Is Observed at The Slowest Flowrate with The Highest Temperature.

Refining and Spotting of a Novel Protein Isolated through Panax quinquefolium and Analysis of its In vitro Antioxidant Effects

Panax quinquefolium is primarily herb in both eastern US and Canada. P. quinquefolium contains a good deal of active ingredients such as phenolic compounds, polysaccharides, essential oil, fatty acids. The main active ingredient is Ginsenoside. Results showed that a single band with an apparent molecular mass of about $15000 \mathrm{Da}$ was shown on SDS-PAGE for the desalted proteins and the content of the novel protein purifiedfrom $\mathrm{P}$. quinquefolius $\mathrm{L}$. measured by Bradford method was $2.42 \mathrm{mg} / \mathrm{mL}$. The elution time of the AGNP was 8.665 min for HPGFC, corresponding to molecular weight of $31,086 \mathrm{Da}$. The relative molecular mass of AGNP was identified as $15,114.70$ $\pm 50 \mathrm{Da}$ for ten different scans. DPPH is a stable free radical that it can accept an electron or hydrogen to become a stable molecule and DPPH shows maximum absorbance at $517 \mathrm{~nm}$ in ethanol. The DPPH scavenging effect elevated with the increasing quantity of AGWSPS, AGCNP, and AGNP at a range of $0.2-3.0 \mathrm{mg} / \mathrm{mL}$, the scavenging activity ranged from $13.12 \%$ to $69.75 \%, 16.02 \%$ to $82.85 \%$, and $19.96 \%$ to 95.15 .It has been concluded that our study might contribute to a rational basis for the application of the antioxidant proteins isolated from American ginseng as suitable candidate for exploring functional foods or 
drugs for the therapy of diseases associated with oxidative stress.

\section{Refinement of Low-Plenitude Lysozyme in Egg White by Means of Free-Flow Electrophoresis with Gel Filtration Chromatography}

Free-Flow Electrophoresis Has Not Been Used for Purification of Low-Abundance Protein in Complex Sample Matrix. Lysozyme in Complex Egg White Matrix Was Chosen as The Model Protein for Demonstrating the Purification of Low-Content Peptide Via an FFE Coupled with Gel Filtration Chromatography. The Fractions with Lysozyme Activity Were Condensed Via Lyophilization. A Special Poly (Acrylamide- Co-Acrylic Acid) (P(AMCo-AA)) Gel Electrophoresis and A Mass Spectrometry Were Used for Identification of Lysozyme.The Two Units Processes of FFZE And GFC As Well as Lyophilization. The Lyophilized Powder Containing Target Low-Abundance Peptides Was Separated Via the First Unit Process Of FFZE. The Collected Fractions from the 10th-18 ${ }^{\text {th }}$ Outlet Were Subjected to The Concentration Via the Second Unit Operation of Lyophilization. To Facilitate Its Further Purification Via He Third Unit Process of GFC The Fractions Were Concentrated to A Certain Concentration. Thus the FFZE Could Be Well Designed as The First Unit Process Without Systematic Optimization for Efficiently Separating the Target from The Complex Egg White Matrix. A Novel Procedure of FFE Coupled with GFC Was Developed for Highly Efficient Purification of Low-Abundance Lysozyme from The Crude Egg White Sample. The Experimental Conditions Of FFZE For The Separation Of Crude Lysozyme In Egg White Were Firstly Optimized As: $4.9 \mathrm{Ml} / \mathrm{Min}$ Background Buffer Of 20 $\mathrm{Mm}$ Ph 5.5 Tris-Acetic Acid, $350 \mathrm{~V}$ And $14^{\circ} \mathrm{Cas}$ Well As $2 \mathrm{Mg} / \mathrm{Ml}$ Protein Content Of Crude Sample. It Was Unveiled That the Separation Resolution of FFE Was Greatly Affected by The Hydrodynamic Flow of Background Buffer in FFE Chamber.

\section{IV.CONCLUSION}

The review show purification techniques used to purify the proteins.

\section{Acknowledgement}

We would like to thank our supervisor, Professor Bharat Kwatra, from Invenzion Labs. Whose expertise was invaluable in formulating the research questions, methodology and drawing Conclusions. His insightful feedback and Guidance pushed us to sharpen our thinking and brought our work to a higher level.

\section{REFERENCES}

[1]. Tan, Z. jian, Li, F. fang, Xu, X. lei \& Xing, J. min. Simultaneous extraction and purification of aloe polysaccharides and proteins using ionic liquid based aqueous two-phase system coupled with dialysis membrane. Desalination 286, 389393 (2012).

[2]. Palanirajan, S. K., Govindasamy, P. \& Gummadi, S. N. Polystyrene adsorbents: rapid and efficient surrogate for dialysis in membrane protein purification. Sci. Rep. 10, 1-9 (2020).

[3]. Gelunaite, L., Lukša, V., Sudžiuviene, O., Bumelis, V. \& Pesliakas, H. Chelated mercury as a ligand in immobilized metal ion affinity chromatography of proteins. J. Chromatogr. A 904, 131-143 (2000).

[4]. GK, M. When to Avoid Dialysis during Protein Purification? Adv. Ind. Biotechnol. 2, 1-5 (2019).

[5]. Chromatography, A. A OVERVIEW ON AFFINITY CHROMATOGRAPHY: A REVIEW Anusha, Shyamala, P.Sirisha. 8, (2018).

[6]. Lalli, E., Silva, J. S., Boi, C. \& Sarti, G. C. Affinity membranes and monoliths for protein purification. Membranes (Basel). 10, (2020). 
[7]. Hilbrig, F. Protein purification by affinity precipitation. J. Chromatogr. B 245, (2003).

[8]. Scheich, C., Sievert, V. \& Büssow, K. An automated method for high-throughput protein purification applied to a comparison of His-tag and GST-tag affinity chromatography. BMC Biotechnol. 3, 1-8 (2003).

[9]. Ko, C. C., Ostermeier, M. \& Lin, S. C. Dual column approach for the purification of zinc finger proteins by immobilized metal affinity chromatography. Process Biochem. 73, 204-210 (2018).

[10]. Wilchek, M. \& Chaiken, I. An overview of affinity chromatography. Methods Mol. Biol. 147, 1-6 (2000).

[11]. Steen, J., Uhlén, M., Hober, S. \& Ottosson, J. High-throughput protein purification using an automated set-up for high-yield affinity chromatography. Protein Expr. Purif. 46, 173178 (2006).

[12]. Xu, M., Bailey, M. J., Look, J. \& Baneyx, F. Affinity purification of Car9-tagged proteins on silica-derivatized spin columns and 96-well plates. Protein Expr. Purif. 170, 105608 (2020).

[13]. B. Coelho, L. C. B., S. Santos, A. F., H., T., S. Correia, M. T. \& G. Paiv, P. M. Protein Purification by Affinity Chromatography. Protein Purif. (2012) doi:10.5772/29947.

[14]. Urtasun, N. et al. Lactoperoxidase purification from whey by using dye affinity chromatography. Food Bioprod. Process. 103, 58-65 (2017).

[15]. Chung, J. A. et al. Purification of prenylated proteins by affinity chromatography on cyclodextrin-modified agarose. Anal. Biochem. 386, 1-8 (2009).

[16]. Nasiri, H. et al. Production and purification of polyclonal antibody against $F\left(a^{\prime}\right) 2$ fragment of human immunoglobulin G. Vet. Res. FORUM 8, (2017).
[17]. Singh, S., Sharma, S. \& Agarwal, S. K. A simple purification procedure of buffalo lung cathepsin $\mathrm{H}$, its properties and influence of buffer constituents on the enzyme activity. Biochem. Biophys. Reports 22, (2020).

[18]. Erban, T. Purification of tropomyosin, paramyosin, actin, tubulin, troponin and kinases for chemiproteomics and its application to different scientific fields. PLoS One 6, (2011).

[19]. Saud Al-Bagmi, M. et al. An efficient methodology for the purification of date palm peroxidase: Stability comparison with horseradish peroxidase (HRP). Saudi J. Biol. Sci. 26, (2019).

[20]. Zhang, D. P., Wu, Z. Y., Li, X. Y. \& Zhao, Z. X. Purification and identification of a 42kilodalton abscisic acid-specific-binding protein from epidermis of broad bean leaves. Plant Physiol. 128, (2002).

[21]. Banik, S., Biswas, S. \& Karmakar, S. Extraction, purification, and activity of protease from the leaves of Moringa oleifera. F1000Research 7, (2018).

[22]. Yang, S. et al. Purification and characterization of an antioxidant protein from fertilized eggs. Korean J. Food Sci. Anim. Resour. 36, (2016).

[23]. Kamble, R. D. \& Jadhav, A. R. Isolation, purification, and characterization of xylanase produced by a new species of bacillus in solid state fermentation. Int. J. Microbiol. (2012) doi:10.1155/2012/683193.

[24]. Zou, C. S., Cao, C. W., Zhang, G. C., Wang, Z. Y. \& Zhu, Y. C. Purification, characterization, and sensitivity to pesticides of carboxylesterase from dendrolimus superans (Lepidoptera: Lasiocampidae). J. Insect Sci. 14, (2014).

[25]. Kabytaev, K. et al. Two-step ion-exchange chromatographic purification combined with reversed-phase chromatography to isolate Cpeptide for mass spectrometric analysis. J. Sep. Sci. 39, (2016). 
[26]. Li, J. et al. Purification and characterization of a novel antifungal protein from Bacillus subtilis strain B29. J. Zhejiang Univ. Sci. B 10, (2009).

[27]. Holzer, M. et al. Refined purification strategy for reliable proteomic profiling of HDL 2/3: Impact on proteomic complexity. Sci. Rep. 6, (2016).

[28]. Hong, Z. W., Yang, Y. C., Pan, T., Tzeng, H. F. \& Fu, H. W. Differential effects of DEAE negative mode chromatography and gelfiltration chromatography on the charge status of Helicobacter pylori neutrophil-activating protein. PLoS One 12, (2017).

[29]. Duong-Ly, K. C. \& Gabelli, S. B. Gel filtration chromatography (size exclusion chromatography) of proteins. in Methods in Enzymology vol. 541 (2014).

[30]. Dong, S. et al. Purification of low-abundance lysozyme in egg white via free-flow electrophoresis with gel-filtration chromatography. Electrophoresis 41, (2020).

[31]. Nadeem, M., Qazi, J. I., Syed, Q. \& Gulsher, M. Purification and characterization of an alkaline protease from Bacillus licheniformis UV-9 for detergent formulations. Songklanakarin J. Sci. Technol. 35, (2013).

[32]. Kong, D. Y. C. et al. Effects of bed compression on protein separation on gel filtration chromatography at bench and pilot scale. J. Chem. Technol. Biotechnol. 93, (2018).

[33]. Pavlov, G. \& Hsu, J. T. Modelling the effect of temperature on the gel-filtration chromatographic protein separation. Comput. Chem. Eng. 112, (2018).

[34]. Rupachandra, S. \& Sarada, D. V. L. Induction of apoptotic effects of antiproliferative protein from the seeds of Borreria hispida on lung cancer (A549) and cervical cancer (HeLa) cell lines. Biomed Res. Int. 2014, (2014).

[35]. Xia, Z. J. et al. Comparison of antimicrobial peptide purification via free-flow electrophoresis and gel filtration chromatography. Electrophoresis 38, (2017).

[36]. Lakshmi, B. K. M., Muni Kumar, D. \& Hemalatha, K. P. J. Purification and characterization of alkaline protease with novel properties from Bacillus cereus strain S8. J. Genet. Eng. Biotechnol. 16, (2018).

[37]. Mitulović, G. \& Mechtler, K. HPLC techniques for proteomics analysis - A short overview of latest developments. Briefings in Functional Genomics and Proteomics vol. 5 249-260 (2006).

[38]. Riek, U., Ramirez, S., Wallimann, T. \& Schlattner, U. A versatile multidimensional protein purification system with full internet remote control based on a standard HPLC system. Biotechniques 46, (2009).

[39]. Ali, I., Aboul-Enein, H. Y., Singh, P., Singh, R. \& Sharma, B. Separation of biological proteins by liquid chromatography. Saudi Pharmaceutical Journal vol. 18 59-73 (2010).

[40]. Gatlin, C. L., Eng, J. K., Cross, S. T., Detter, J. C. \& Yates, J. R. Automated identification of amino acid sequence variations in proteins by HPLC/microspray tandem mass spectrometry. Anal. Chem. 72, 757-763 (2000).

[41]. Mills, J. B., Mant, C. T. \& Hodges, R. S. Onestep purification of a recombinant protein from a whole cell extract by reversed-phase highperformance liquid chromatography. J. Chromatogr. A 1133, 248-253 (2006).

[42]. Mcdonald, W. H., Ohi, R., Miyamoto, D. T., Mitchison, T. J. \& Yates, J. R. Comparison of three directly coupled HPLC MS/MS strategies for identification of proteins from complex mixtures: single-dimension LC-MS/MS, 2-phase MudPIT, and 3-phase MudPIT. International Journal of Mass Spectrometry vol. 219 (2002).

[43]. Jadaun, G. P. S. et al. HPLC for Peptides and Proteins: Principles, Methods and Applications. Pharm. Methods 8, (2017). 
[44]. Wang, H. Y., Zhang, Y. Q. \& Wei, Z. G. Excess acetone extraction in silk protein solution greatly accelerates the regeneration progress of silk fibroin for desalting and purification. Int. J. Biol. Macromol. 146, 588-595 (2020).

\section{Cite this article as :}

Angela Boxi, Isha Parikh, Radhika B S, Shryli K S, "Current trends in protein purification : A Review", International Journal of Scientific Research in Science and Technology (IJSRST), Online ISSN : 2395-602X, Print ISSN : 2395-6011, Volume 7 Issue 6, pp. 279-310, November-December 2020. Available at doi $\quad$ : https://doi.org/10.32628/IJSRST207645

Journal URL : http://ijsrst.com/IJSRST207645 